\title{
Effectiveness of Digital Technologies to Support Nursing Care: Results of a Scoping Review
}

This article was published in the following Dove Press journal:

Journal of Multidisciplinary Healthcare

\author{
Kai Huter (D) ${ }^{1,2}$ \\ Tobias Krick $\mathbb{D}^{1,2}$ \\ Dominik Domhoff $\mathbb{I D}^{2,3}$ \\ Kathrin Seibert ${ }^{2,3}$ \\ Karin Wolf-Ostermann (iD) ${ }^{2,3}$ \\ Heinz Rothgang (D) ${ }^{1,2}$ \\ 'University of Bremen, SOCIUM \\ Research Center on Inequality and Social \\ Policy, Bremen, Germany; ${ }^{2}$ University of \\ Bremen, High-Profile Area of Health \\ Sciences, Bremen, Germany; ${ }^{3}$ University \\ of Bremen, Institute for Public Health and \\ Nursing Research, Bremen, Germany
}

Correspondence: Kai Huter Universität Bremen, SOCIUM Forschungszentrum Ungleichheit und Sozialpolitik, Abteilung Gesundheit, Pflege und Alterssicherung, Mary-SomervilleStraße 3, Bremen 28359, Germany

Tel +49-42I 218-58 547

Email huter@uni-bremen.de
Background: The field of digital technologies being developed or applied to support nursing care is extensive. The aim of this scoping review is to provide an overview on technologies for which results on positive or negative effects on persons in need of care, caregivers or care institutions are available and to appraise the reliability of these results.

Methods: A scoping review design has been used to identify studies focussing on the effectiveness of digital technologies in nursing care for persons in need of care, caregivers or care institutions. The screening process included 19,510 scientific publications from 9 databases.

Results: A total of 123 single studies and 31 reviews were subjected to the analysis. The included technologies comprise nursing and health information technologies, such as assistive devices, information and communication technologies, sensors and robotics. The results show that there are many studies that demonstrate positive effects, but the level of evidence is mostly low and study sizes are often small. Hardly any technology has been researched intensively enough to produce conclusive results. Studies on a high level of evidence (RCTs) lack for most technological areas. Heterogeneous results in some areas indicate that effects may depend strongly on the mode and specific context into which the technologies are introduced.

Conclusion: Due to the limited evidence on effectiveness of digital technologies in nursing care, it is not surprising that care institutions are reluctant to put innovative technologies into practice. The scoping review indicates technology areas that should be subject to future research with higher quality studies. Research on outpatient, informal and cross-sectoral care should be intensified to further exploit the potential of digital technologies with a view to improving independence of care-recipients and unburdening formal and informal carers.

Keywords: innovative technology, care-dependent, caregivers, nurses, patients

\section{Background}

Research on digital technologies for nursing care is carried out in many countries in the hope that these technologies may facilitate or even substitute some aspects of human nursing work and thus contribute to mitigate the rapidly rising costs of care and shortages of skilled workers. ${ }^{1-4}$ There are already shortages of nursing care staff in many countries and these are expected to intensify due to demographic changes. ${ }^{5}$ Yet available digital technologies for nursing care are often not adopted in nursing practice. ${ }^{6}$ To bridge this gap, the German Federal Ministry of Education and Research (BMBF) has financed a project entitled "Nursing Care Innovation Centre" (Pflegeinnovationszentrum) as part of the research cluster on "The Future of Nursing Care". Its goal is to develop innovative technologies, evaluating 
promising technologies and promoting their implementation. As a first step, the project team has been tasked with creating an overview of the technologies for which promising or reliable results are already available and that show beneficial effects on persons in need of care, including patients in hospitals, their caregivers or the settings in which care is provided.

The possible effects that these technologies aim at cover a wide-ranging field. ${ }^{7-9}$ The quality of life (QoL) of people in need of care may be improved, ${ }^{10-12}$ and the independence of people potentially in need of care may be supported by technology such that they are able to continue living independently at home with minimum or no nursing support. ${ }^{13-16}$ Psychological or physical support for formal caregivers can have a beneficial effect on their health $^{17,18}$ and thus might, for instance, enable older employees to work longer; support for informal caregivers may relieve them to the extent that they can cope without additional formal care support. ${ }^{19-23}$ In hospitals or longterm care institutions, nursing staff may be supported in working more effectively, providing better quality care, or improving patient safety. ${ }^{24-27}$ These effects could be achieved by means of direct care support or an improved, technologically supported organization of care processes. Nursing work could also be facilitated by improving the organization of handover processes or cooperation between different institutions. ${ }^{28,29}$

The field of digital technologies under development or already applied to support nursing care is very extensive. ${ }^{30}$ This scoping review focuses on technology that supports a formal or informal caregiver in their caring activities, or directly supports a person in need of care. Support for persons in need of care may refer to social, mental and/ or physical support that improves the care provided or helps to maintain, improve or regain independence.

The aim of this scoping review is to provide an overview of technologies or areas of technology for which results are available on positive or negative effects on persons in need of care, caregivers or institutions. An additional focus is on the quality of these results. To address this question, we assessed the study types of the included studies. Due to the large number of included studies a full assessment of the quality of each study was not possible. Study types are used as a proxy because they have a decisive influence on the level of evidence that may be achieved.

The review is based on the following main research questions: 1 . Which digital technologies for nursing care have already been evaluated in terms of effectiveness outcomes that are relevant for persons in need of care, formal or informal caregivers or care institutions? 2. For which technologies is there reliable empirical evidence of positive or negative effects on care outcomes or care processes? 3. Which care settings and which target groups have been addressed by this kind of research so far?

\section{Methods}

This study was conducted using a design based on Arksey and O'Malley's scoping review framework, which allows the inclusion of a wide range of study designs to provide a broad overview of the research field. ${ }^{31}$ The research process was enhanced using processual recommendations found in Levac et $\mathrm{al}^{32}$ - this concerned in particular the iterative selection process of the studies. The scoping review started with a rather broad research question. To enable more detailed analyses on the effectiveness results, the question was refined during the research process. The first research question that guided the initial search process was: which areas of digital technologies aiming to support informal or formal care are most frequently researched with respect to acceptance, effectiveness and efficiency?

The aim of the question was to generally map out the field of research on digital technologies in nursing care. The analysis related to this research question is published in Krick et al. ${ }^{30}$ The research question was specified further for a second evaluation phase which focussed on effectiveness studies, allowing not only to identify areas in which studies on effectiveness are carried out but also to identify the technologies that are effective and those that are not.

\section{Search Strategy}

We used nine electronic databases for our search: Medline, Scopus, CINAHL, Cochrane Library, ACM Digital Library, IEEE Xplore, the Collection of Computer Science Bibliographies, GeroLit and CareLit. An additional hand-search of relevant projects from Germanspeaking countries was carried out to supplement the results. The search included scientific papers that were published between 2011 and 2018 and contained empirical studies (abstracts available) in German or English language. All databases were searched in March 2018. The considered time period was limited to seven years in order to make the scope manageable and focus on the most innovative developments.

Details on the full initial search strategy, study identification and data extraction process are published in Krick 
et al. ${ }^{30}$ The study identification process included the screening of 19,510 scientific publications. The following English search terms were used for the search:

(Care OR Caring OR Nursing) AND (Technol* OR Robot* OR Intelligent OR Smart OR Assistive OR Decision Support System OR Ambient Assisted Living OR Sensor OR Wearable OR Virtual Reality OR Mixed Reality OR Tagging OR Tracking OR Remote Health Monitoring OR Fall Detection OR Human Computer Interaction OR Human Machine Interaction OR Gerontotechnology OR Gerontechnology OR Head Mounted Display OR Exoskeleton OR Augmented Reality OR Biomedical Monitoring) AND (Effectiveness OR Efficacy OR Effect OR Efficiency OR Acceptance OR Adoption OR Acceptability HTA OR Health Technology Assessment OR Evaluation OR Evaluations OR CostBenefit Analysis OR Cost Benefit OR Cost Effectiveness OR Cost Utility OR Cost Analysis OR Cost Analyses OR Cost Consequence OR Economic Evaluation OR Economic Evaluations OR Economic Analysis OR Economic Analyses OR Costs and Benefits OR Benefits and Costs OR Costs and Outcomes OR Marginal Analysis).

\section{Selection of Studies}

The search and study selection process based on the first wider research question resulted in the identification of 715 studies. $^{30}$ To focus the analysis on effectiveness results that are relevant for persons in need of care, formal or informal caregivers or care institutions, all studies were excluded that focussed on acceptance or efficiency results only (eg, economic modelling studies), targeted an educational setting or were situated in laboratory settings only. Based on these restrictions, 212 single studies and 48 reviews were subjected to a more detailed data extraction that focussed especially on the type, target group and content of the reported outcomes. Single quantitative and qualitative studies were only included in the final analysis and presentation of results if they evaluated an effectiveness-outcome that implies a direct benefit for a person in need of care, a caregiver or an institution. Studies with effectiveness outcomes that referred only to technical effectiveness or usability were not included.

Reviews were included if they provided at least a basic systematic quality assessment of the studies included, ie, systematic reviews, integrative reviews and meta-analyses. This decision is based on the fact that it was impossible to judge the relevance of the reported results if they were presented without reference to the studies' quality. Systematic or integrative reviews that did not include at least a basic quality assessment of the included studies were not categorized as systematic reviews, even if this was their self-designation, and excluded from the analysis. Systematic reviews were also excluded if none of the studies included matched the eligibility criteria of this review or if it was not ascertainable to which specific technological application the results referred.

The full study selection process and reasons for the exclusion of studies are presented in the flow diagram in Figure 1.

\section{Data Extraction}

The data extraction of the studies in the first phase of analysis included information on the technology category, study type, study setting, country, number of study participants, target population, target setting, field of support and addressed problem. ${ }^{30}$ For the in-depth analysis of the single studies, the main focus was the presented effectiveness results. The results were categorized as being related to the person in need of care, the caregiver, the institution or referring to the technical effectiveness of the technology. For each of these categories it was assessed whether the reported effect was positive, negative, neutral or ambivalent (ie, positive or neutral effects that were accompanied by some negative effects). The type of effect in each category was documented in detail. The data extraction of the first phase with respect to technology categories, study type, study setting and number of study participants was double-checked. Some studies included effectiveness and acceptance results. If these outcome dimensions were assessed using different methods or different sample sizes, only the relevant information for the effectiveness results is presented or reported in this review.

The studies were categorized under the following technology categories: ambient assisted living (AAL), assistive devices, information and communication technologies (ICT), monitoring/sensors, robotic technologies and virtual reality. Definitions for the categories are given below in the technology-specific result sections.

For the in-depth analysis of the reviews, the data extraction focused on the type of review, main topic and/ or included technologies of interest, search period, number of studies included, the main results with respect to effectiveness as stated by the authors, and a short resume on the methodological quality of the included studies or study limitations according to the authors.

The data extraction of the single studies was done by one researcher and double checked by a second researcher. 


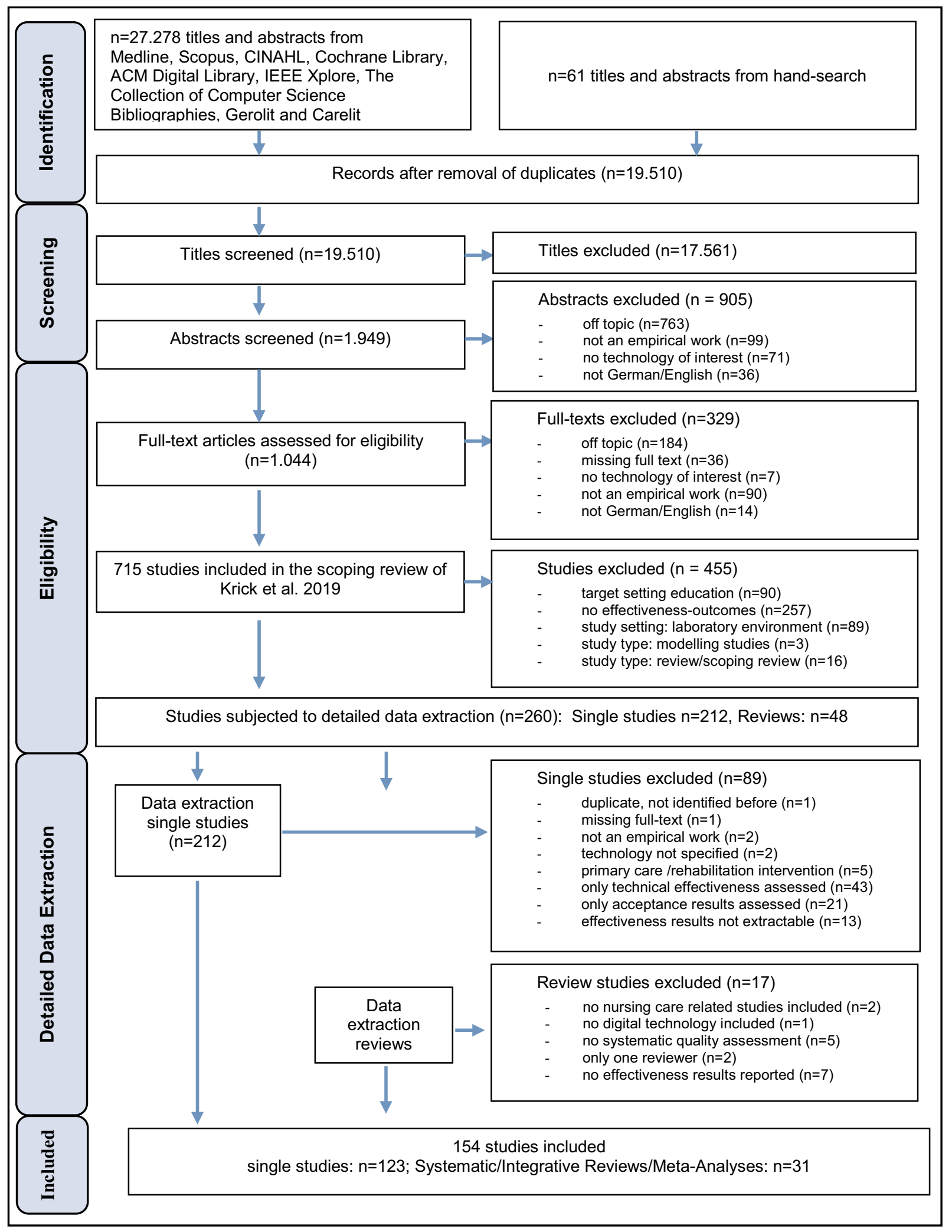

Figure I Flowchart: Documentation of study selection process.

In case of a disagreement, results were discussed between the two researchers to achieve a consensus. The data extraction for the systematic reviews was carried out by one researcher, reviews that were excluded because of a missing quality appraisal were double-checked by a second researcher. 


\section{Assessment of Level of Evidence}

In order to give the best possible indication of the reliability of the results, an evidence level was assigned to the study designs included, based on common evidence-based nursing and evidence-based medicine guidelines, ${ }^{33,34}$ as shown in Table 1. The categorisation in these guidelines refers to "well-designed" studies, this is set in parentheses in the table as we could not assess the study quality in detail. The category "user studies" is used for research designs that are in general not used in nursing or health research but encompass research designs that are used in technology research. These studies have mostly only few participants and are used in rather early phases of technology development. Studies with control groups are categorized in this group if they include less than 10 persons in the intervention group and do not provide sample size calculations (power calculation) or test statistics. Systematic reviews are rated on the basis of the highest evidence-level studies that are included in the review.

\section{Results}

\section{Search Results}

In total, 123 single studies and 31 reviews have been included in the detailed analysis of study results (direction of results and type of outcomes), target groups and settings, study type (level of evidence) and study size.

Table I Level of Evidence Scale

\begin{tabular}{|l|l|}
\hline $\begin{array}{l}\text { Level of } \\
\text { Evidence }\end{array}$ & Study Type \\
\hline Ia & $\begin{array}{l}\text { Systematic reviews and meta-analyses that include } \\
\text { more than one (well-designed) randomized } \\
\text { controlled trial (RCT) }\end{array}$ \\
\hline Ib & (Well-designed) RCT \\
\hline 2 & $\begin{array}{l}\text { (Well-designed) controlled studies, without } \\
\text { randomisation, ie quasi-experiments; or pilot RCTs } \\
\text { (self-designated) }\end{array}$ \\
\hline 3 & $\begin{array}{l}\text { (Well-designed) case-control or cohort studies, } \\
\text { (preferably from more than one centre or research } \\
\text { group) }\end{array}$ \\
\hline 4 & $\begin{array}{l}\text { Findings obtained from descriptive, other } \\
\text { observational and/or qualitative research designs } \\
\text { (including case studies), cross-sectional studies, } \\
\text { user studies }\end{array}$ \\
\hline
\end{tabular}

\section{General Results}

The main research questions aim at identifying digital technologies that have already been evaluated with regard to effects on people in need of care, formal or informal carers or care institutions, and specifically at identifying technologies for which reliable empirical results on positive effects are available. As the reliability of the results is dependent on the study types and study sizes that have been performed, these are presented below before the field of included technologies and specific effectiveness results are displayed in more detail. A detailed overview of the results of all single studies is provided in Additional File 1 (including information on study type and size, target setting, target group, direction and type of effect). An overview on the systematic reviews and their main characteristics is provided in Additional File 2.

\section{Technology Categories and Study Types}

Table 2 shows the number of studies in each technology category, differentiated by study type. More than half of the studies are on ICT. The ICT category comprises a wide range of technologies, so we subdivided this category into the subcategories communication support, decision support, electronic health records (EHR)/electronic medical records (EMR), hospital (or care institution) information systems (HIS), specific software applications/apps, telecare, process planning/data exchange and target-specific interfaces. Amongst these, EHR/ EMR is the largest category. The second largest category overall is robotic technology with 24 , or $20 \%$ of all studies, followed by monitoring/sensor applications with 17 studies (14\%). The differentiation by study type shows an overall low level of evidence. Of all studies, $16 \%$ are RCTs - with often rather small sample sizes (see Table 3). The most common study type is the quasi-experimental design (34 studies, or $28 \%$ ), which includes non-randomized controlled trials and pre-/post-designs. The size and the quality of these studies is quite diverse, so their results should be assessed with care. Another common study type is the case study (23 studies, or 19\%). Case studies differ widely in their specific design; some are in-depth analyses of work process changes within an institution, others are small and based on a few interviews only. Only nine of the studies are cross-sectional, cohort or case control studies, and have all been conducted in the US.

\section{Study Sizes}

Most of the results in this scoping review are based on relatively small studies. Table 3 presents an overview of the number of study participants or institutions included in the 


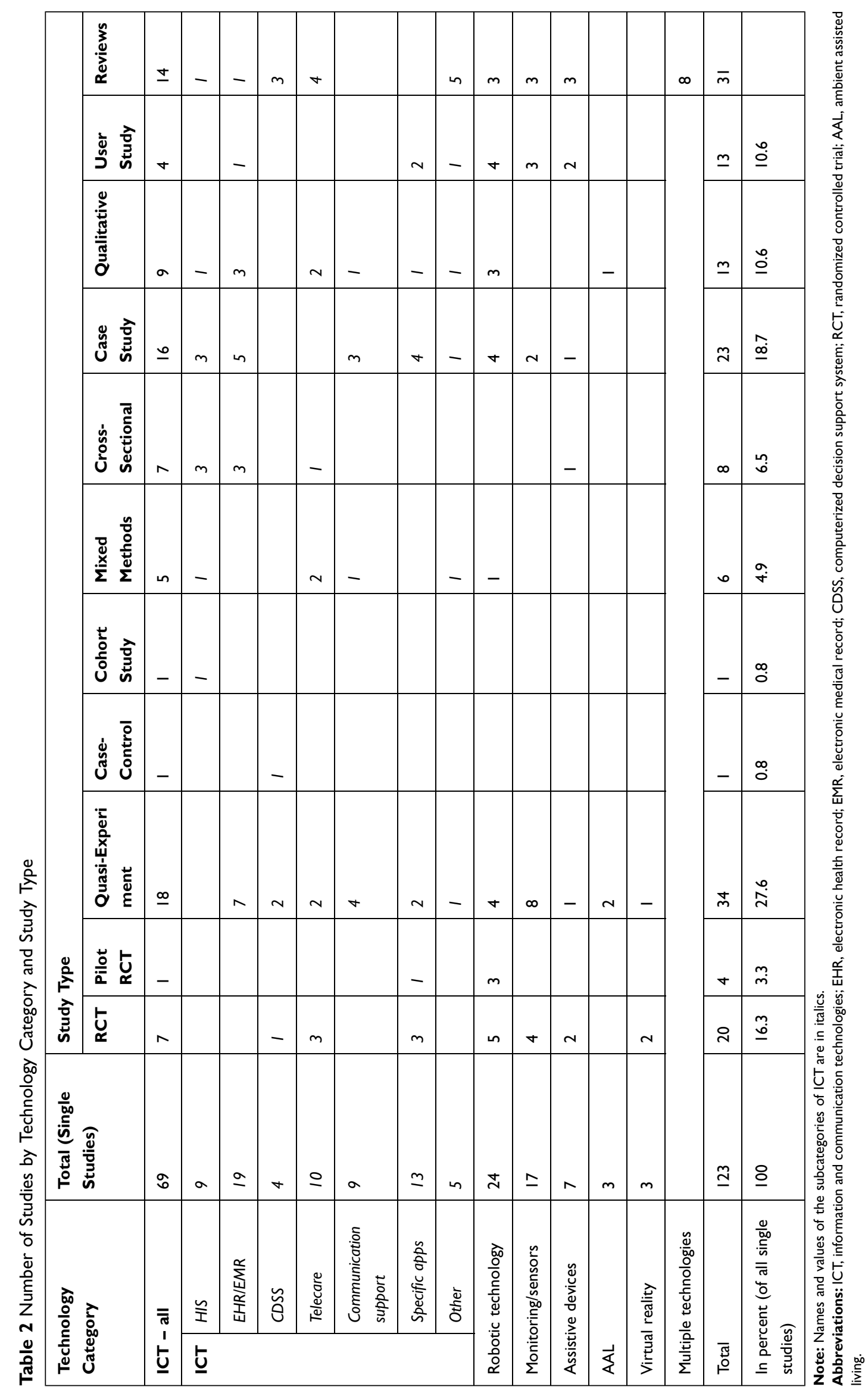


Table 3 Number of Studies by Study Type and Size of Studies

\begin{tabular}{|c|c|c|c|c|c|c|c|}
\hline \multirow[t]{2}{*}{ Study Type } & \multirow[t]{2}{*}{ Level of Evidence } & \multirow[t]{2}{*}{ Total } & \multirow[t]{2}{*}{ Studies on Institutions (i) (Number of i) } & \multicolumn{4}{|c|}{ Number of Study Participants ${ }^{a}$} \\
\hline & & & & $<30$ & $30-100$ & $101-300$ & $>300$ \\
\hline RCT & $\mathrm{Ib}$ & 20 & 2 (i: $5-12$ ) & 7 & 3 & 5 & 3 \\
\hline Pilot RCT & 2 & 4 & - & 3 & 1 & & \\
\hline Quasi-experiment & 2 & 34 & 4 (i: I-27I) & 11 & 12 & 3 & 4 \\
\hline Case control study & 3 & 1 & - & - & 1 & - & - \\
\hline Cohort study & 3 & I & I (i: 1248) & - & - & - & - \\
\hline Mixed methods & 4 & 6 & I (i: 5) & 2 & 2 & - & I \\
\hline Cross-sectional study & 4 & 8 & 7 (i:5-2603) & - & - & I & - \\
\hline Case study ${ }^{\mathrm{b}}$ & 4 & $22^{\mathrm{b}}$ & 9 (i: I-3) & 8 & 4 & I & - \\
\hline Qualitative study & 4 & 13 & - & 9 & 3 & I & - \\
\hline User study & 4 & 13 & - & 8 & 5 & - & - \\
\hline Total & & $123^{\mathrm{b}}$ & 24 & 48 & 31 & 11 & 8 \\
\hline In percent & & 100 & 19.6 & 39.3 & 25.4 & 9.0 & 6.6 \\
\hline
\end{tabular}

Notes: ${ }^{\mathrm{a}}$ For studies with intervention and control groups the size of the intervention group is indicated. ${ }^{\mathrm{b}}$ For one case study, the number of participants has not been indicated.

studies. Overall, $39 \%$ of all studies had less than 30 participants and only $16 \%$ of the studies are based on more than 100 study participants., so most of the studies are quite small. About $20 \%$ of the studies were performed on an institutional level, these are especially the case studies and cross-sectional studies. The number of institutions included varies widely.

\section{Direction of Results}

This review aims at identifying types of technologies that show promising positive results with respect to outcomes that directly affect persons in need of care, formal or informal caregivers or the effectiveness of a care institution. Overall, $74 \%$ of the studies included reported positive results, $15 \%$ reported ambivalent results, ie, the studies yielded positive and negative results for different outcome dimensions. Eleven percent of the studies could not identify any (statistically significant) effect of the technology and no study reported pure negative impacts. Table 4 depicts the direction of the analysed outcomes of the studies by study type. It is noteworthy that the higher the evidence level of the study, the lower the proportion of positive results. The RCTs included have only $60 \%$ positive results and, at $30 \%$, the highest share of neutral results, while the user studies report positive results for $92 \%$ of the studies. An exception are the mixed methods studies, of which $50 \%$ report ambivalent results.

\section{Study Results in Detail by Technology Categories}

In the following, the specific technologies that are included in this review and the general direction of the results are presented in more detail by technology categories. This will be introduced by a short definition of each category. A detailed overview of all results of the single studies is presented in Additional File 1.

If there are relevant systematic reviews for the specific technological area in questions, these are mentioned in the corresponding parts of the text. Many of the systematic reviews comprise a wide range of technologies, some of them are focussed on specific care problems and include only very few studies on digital technologies. It is therefore not possible to provide a focussed summary of all systematic reviews within the scope of this paper. All systematic reviews or metaanalyses that are included in this scoping review are listed in Additional File 2. Most systematic reviews conclude or state that the quality of the studies included is only moderate or poor and that high-quality evidence is missing. Many of them state that the studies are highly heterogeneous and hardly comparable. Nevertheless, these studies help to show the breadth of analysed technologies. High-quality results are only available for very few specific technologies.

\section{Information and Communication Technologies (ICT)} ICT comprise a wide set of technologies. In general, they can be defined as technologies that collect, store, provide, manage and/or improve interpersonal communication. We differentiate the included technologies according to the following subcategories: 
Table 4 Direction of Results by Study Type in Percent

\begin{tabular}{|c|c|c|c|c|c|c|}
\hline \multirow[t]{2}{*}{ Study Type } & \multirow[t]{2}{*}{ Level of Evidence } & \multirow[t]{2}{*}{ Number of Studies } & \multirow[t]{2}{*}{ In Percent } & \multicolumn{3}{|c|}{ Direction of the Results } \\
\hline & & & & Positive & Neutral & Ambivalent \\
\hline $\mathrm{RCT}$ & Ib & 20 & 16.3 & 60.0 & 30.0 & 10.0 \\
\hline Pilot RCT & 2 & 4 & 3.3 & 75.0 & & 25.0 \\
\hline Quasi-experiment & 2 & 34 & 27.6 & 76.4 & 14.7 & 8.8 \\
\hline Case-control study & 3 & 1 & 0.8 & 100.0 & & \\
\hline Cohort study & 3 & I & 0.8 & 100.0 & & \\
\hline Mixed methods & 4 & 6 & 4.1 & 33.3 & 16.7 & 50.0 \\
\hline Cross-sectional study & 4 & 8 & 6.5 & 75.0 & 12.5 & 12.5 \\
\hline Case study & 4 & 23 & 18.7 & 78.3 & 4.3 & 17.4 \\
\hline Qualitative study & 4 & 13 & 10.6 & 76.9 & & 23.1 \\
\hline User study & 4 & 13 & 10.6 & 92.3 & & 7.7 \\
\hline Total & & 123 & 100.0 & 74.0 & II.4 & 14.6 \\
\hline
\end{tabular}

1. Hospital (or care institution) information systems (HIS)

2. Electronic health (EHR)/electronic medical records (EMR)

3. Computerized decision support systems (CDSS)

4. Telecare

5. General communication support

6. Systems to support process planning and/or data exchange

7. Specific Apps

8. Target group specific interfaces

The category "Specific Apps" comprises applications that do not fit in any of the other categories; it includes software solutions that support professionals, informal caregivers or care-dependents in diverse ways. HIS and EHR/ EMR are mostly highly integrated systems that often comprise some of the technologies included in the other subcategories, as, for example, computerized decision support systems.

Hospital/Care Institution Information Systems (HIS)

HIS are systems that collect, store, manage and transmit data in hospitals or other care institutions that focus on operational management systems, specific organizational systems or comprise patients' EMRs and/or other organizational systems.

This category comprises nine studies. Four of these are rather large cross-sectional or cohort studies on HIS in hospitals. Three of them identify positive effects on patient safety indicators ${ }^{27}$ or mortality rates. ${ }^{35,36}$ Especially interesting are the ambivalent results of a study by Angst et al. ${ }^{37}$
This study demonstrates in a large cross-sectional analysis of hospitals in the United States (US) that positive effects of cardiology information technology (IT) on mortality, and negative effects of administrative IT on interpersonal care depend on the extent of IT implementation. Mortality rates were especially low in hospitals with very high and very low levels of cardiology IT. Results on interpersonal care were low if hospitals had very much or very little administrative IT. This indicates, according to the authors, that an over- or underinvestment in IT can potentially have negative effects on hospitals outcomes, and they conclude that relevant mediating processes and interaction effects have to be analysed carefully when IT is implemented. ${ }^{37}$

Effects of HIS implementation in nursing homes are analysed in three rather small case or mixed method studies only. Two of them focussed on effects on communication intensity and communication patterns, one with ambivalent $^{38}$ results and the other one with positive results. ${ }^{39}$ The third study analysed the time spent on electronic documentation and found ambivalent results. Time spent on documentation increased temporarily because the electronic documentation was not sufficiently aligned with caregivers' documentation practices. ${ }^{40}$ Two single studies focussed on HIS in intensive care units (ICU) ${ }^{41}$ and a HIS subsystem aiming at patient engagement ${ }^{42}$ with positive results. One systematic review on the implementation of computer-based nursing records in residential aged care facilities synthesized the evidence of seven qualitative studies - and concludes that the implementation of electronic documentation systems does not automatically lead to a perceived benefit for the staff, but may often be perceived as an additional burden that complicates daily 
routines. ${ }^{26}$ With the exception of two studies, all studies on HIS were carried out in the US.

Overall, study results on HIS are predominantly positive but based on rather low evidence-level studies. Three studies with ambivalent results indicate that the implementation of complex systems has to be done with care and under consideration of specific work processes so as to avoid unwanted negative effects.

\section{Electronic Health Records/Electronic Medical Records (EHR/EMR)}

EHR and EMR are digital records of patient-related health information. The EMR refers to patient data that is stored and exchanged within an institution, mostly a hospital. An EMR system may include quite a range of different functions. These are often, but not always patient information administration, medication administration, computerized physician order entry (CPOE), decision support or data results management systems, care documentation and sometimes nurse reminder systems. The main focus of the EHR is its capability to exchange information between two systems. Thus, the main applications are electronic patient handover tools and the exchange of health information between different institutions or physicians. While we differentiate between both terms, some publications use both terms synonymously. ${ }^{25}$

This review includes 19 studies on EHR or EMR systems. With the exception of three studies, all of them yield positive results, although the evidence level of most of the studies is rather low. Most studies are situated in hospital settings, and positive effects of EMR systems in general relate to improvements in patient safety, ${ }^{43-45}$ reduced documentation or data access time ${ }^{45,46}$ and improved workflows. ${ }^{46}$ Studies specifically focussing on medication administration observe reduced medication errors and positive effects on guideline adherence. ${ }^{47-51}$ All four studies covering aspects of health information exchange or patient handovers yield positive results in terms of reduced workload or treatment times for caregivers and reduced incomplete documentations or error rates. $^{29,52,53}$ Only one of these studies analysed patientrelated outcomes and identifies lower 30-days readmission rates and fewer emergency return visits. ${ }^{28}$ Two quasiexperimental studies on patient information systems a nurse reminder tool ${ }^{54}$ and a pain notification system ${ }^{55}$ - could not identify any statistically significant positive effects. Only three studies analyse the implementation of EMR systems in long-term care facilities. One of them identifies neutral effects on quality indicators, but small measurable increases in productivity and efficiency. ${ }^{56}$ Another one finds positive effects on quality of care and improved accessibility of information. ${ }^{57}$ The third one is ambivalent in its results: there are positive effects on communication between caregivers and doctors, accessibility of information and safety of care delivery, but the nurses in this study claim that the time spent with the patients is reduced as time spent on documentation is increased, often due to double documentation. ${ }^{58}$

These findings are confirmed by an overview of systematic reviews on EMR/EHR by Reis et al and an extensive systematic review by McKibbon et al on the impact of health IT on medication management processes results in general (including CDSS and CPOE). ${ }^{25,59,60}$ Reis et al conclude that it is possible to identify preliminary benefits of EMR and EHR on quality of care and clinical process outcomes, but that there was no evidence so far of a measurable impact on patient-related outcomes such as mortality, length of stay or cost-effectiveness for the implementing institutions. ${ }^{25}$ McKibbon et al found many studies reporting on improved results for prescribing, ordering and monitoring phases of medication management. Clinical outcomes were sometimes improved, mostly in observational studies, more seldom in controlled trials. Studies on costs or full economic evaluations were especially rare - so they conclude that proof of clinical improvements and economic effectiveness is lacking. ${ }^{59,60}$

Altogether, there are positive results that may be promising for further inquiry, but no strong evidence on clinical outcomes or improved organizational effectiveness. For some neutral and ambivalent results, it is reported that the technology has to be well adapted to the needs of caregivers. Negative results tend to occur when EMR-based documentation is not well integrated into work processes and leads to additional documentation work. $^{54,58}$

\section{Computerized Decision Support Systems (CDSS)}

CDSS are software solutions in which "individual patient data (input) are linked with treatment guidelines and a recommendation (output) for the specific patient is generated" $" 61$ and delivered to a person in charge of care. These systems are sometimes directly integrated in EMR; this review includes four studies that analysed stand-alone CDSS. Many CDSS focus on medical decisions and primary care, and hence are mainly used by physicians. This 
scoping review focusses on CDSS that are used specifically by nurses.

All four studies yield positive results, two of them relate to risk assessment for complex medication regimes $^{62}$ and specific fall risks. ${ }^{63}$ The other two studies evaluated systems for supporting care decisions or guideline compliance by nurses for urinary catheter changes, ${ }^{64}$ and fluid resuscitation in severely burned patients. ${ }^{65}$ There are several systematic reviews on CDSS that identify predominantly positive effects, but the main focus of these reviews is on decision support for physicians. ${ }^{61,66,67} \mathrm{An}$ interesting meta-analysis on $162 \mathrm{RCTs}$, that sought to identify factors that differentiate between effective and ineffective clinical CDSS, concluded that such systems are more likely to succeed if they provide advice for patients as well as practitioners, if they require practitioners to supply a reason for overriding advice or if they were evaluated by their developers. ${ }^{68}$

While there is sound evidence on positive effects of CDSSs in the medical context, the number of studies focussing on nurses or long-term care is still rather scarce; however, there are promising positive results in this field.

\section{Telecare}

For the purpose of this study, telecare is defined as an intervention that involves regular care support from a professional caregiver delivered via digital technologies from a distance. (In contrast to this specific definition, telecare is sometimes defined as any kind of technology that enables a person in need of care to remain living at home or supports their caregiving family members.) Such an intervention can comprise regular care support that is provided by video, telephone, text-messaging or web-based applications, as well as more complex tele-homecaresystems that are enhanced by wearable or ambient sensors, eg, for emergency detection.

Study results in this category are much less positive than in other technology categories. Only 3 of the 10 studies yielded positive results, all of which are situated in outpatient long-term care. ${ }^{69-71}$ In contrast to these, there are three studies without any significant positive effects, ${ }^{72-74}$ and four studies with ambivalent results. ${ }^{75-78}$ The outcomes analysed in these studies are quite diverse.

Four systematic reviews on telecare were identified in this scoping review. ${ }^{23,79-81}$ None of them included any RCTs. Two of them focus on outpatient palliative care. One of these reports studies with positive effects on quality of care, documentation effort, cost, and communications, but none of the studies included described any patientrelevant clinical outcomes. ${ }^{79}$ The other one identifies three studies with clinical outcomes, but none of them was large enough to find significant effects. ${ }^{80}$ The most recent systematic review on telecare in outpatient long-term care settings concludes, on the basis of an analysis of qualitative studies, that experiences with the use of telecare are diverse. The authors stress that the findings indicate that telecare systems can promote safety and security to age in place, but that "one size does not fit all" - they have to suit individual needs and be supported by service providers. ${ }^{81}$

\section{General Communication Support}

There are nine studies included in this scoping review that focus on ICT technologies for supporting communication. Most of them are situated in hospital settings, and the majority supports communication between professionals. The applications are quite diverse; they comprise nursecall or task management systems, hands-free communication systems, a tele-conferencing application for remote support and training of health care providers, and collaboration between hospital and home care by text messaging. ${ }^{82-87}$ Two studies analyse effects of applications that support communication between formal caregivers and non-professionals. One of them analyses a system to support suddenly speechless critical care patients, ${ }^{88}$ the other one establishes text messages to keep relatives updated during operations. ${ }^{89}$ With one exception, all these studies report positive results, but target groups and effect dimensions are quite diverse.

One main outcome that is often improved is communication efficiency and reduction of response times, and one study reports reduced walking distances for nurses. Two studies identify a reduced length of stay for patients. ${ }^{84,86}$ There is only one study reporting ambivalent results: next to an improvement in efficiency, negative effects of the analysed smartphone use in clinical communication refer to more frequent interruptions during face-to-face communication by smart-phone calls and a worsening of interprofessional relationships between physicians and nurses perceived by the latter. $^{90}$

The reviews included are quite diverse in scope as well. Five systematic reviews focus on different communication technologies. They review literature on computergenerated reminders, ${ }^{91}$ digital technologies for pain management in older people, ${ }^{92}$ Internet-based interventions to decrease caregiver stress, ${ }^{19}$ the use of personal digital assistants in clinical settings ${ }^{93}$ or the use of ICT in general 
in nursing practice in Sweden. ${ }^{94}$ There is mostly positive evidence that digital technology may improve care or communication processes. Patient-relevant clinical outcomes are often not researched or no statistically significant effects are proven. The systematic review on strategies to reduce caregiver stress reports ambivalent results: nine of the included studies reported positive benefits, nine yielded only partly positive results and six reported no change on any outcome measure. ${ }^{19}$ Thus, results may differ widely depending on the intervention in question.

\section{Systems to Support Process Planning and/or Data Exchange}

There are only two studies that explore software solutions that support the planning of work processes in care and are not integrated in a HIS or EHR/EMR-system. These are both situated in outpatient long-term care. The level of evidence of these studies is rather low, but they both identify positive results such as positive effects on patient education, quality of care and patient satisfaction. ${ }^{24,95}$

\section{Specific Software/Apps}

This category comprises software-based applications that support caregivers or persons in need of care, whose main focus is not communication and which are not integrated in more complex data management systems as EMR/EHR or HIS.

Most of the studies in this category provide therapeutic support for people with dementia. Four studies, including two RCTs, focus on cognitive stimulation with predominantly positive results. ${ }^{96-99}$ Two studies tested serious games with a quasi-experimental design aiming mainly at physical improvements in inpatient long-term care settings. While one of the studies reported positive results, ${ }^{100}$ the other one found positive results on physical functioning but reported negative effects on emotional performance as a study result. ${ }^{101}$ There is only one study - an RCT - that targets the support of informal caregivers by evaluating a personalized tool to support carers of people with dementias. The study does not report any positive effects on care receivers, but documents an increased sense of competence in caregivers after 12 months of using the tool. ${ }^{102} \mathrm{~A}$ qualitative study on a personal assistant for dementia identifies positive effects on patients, but no effects on the burden on the family. ${ }^{103}$ Four studies in this category provide care support for professionals by providing information about residents, point-of-care documentation or wound monitoring. They all yield positive results, but the level of evidence is low. ${ }^{104-107}$

\section{Target Group Specific Interfaces}

The accessibility of a technology or a technological device is pivotal for its usability. Sometimes technologies cannot fulfil their potential, or produce negative outcomes because their interfaces are not user-friendly enough. Studies on the usability of interfaces are often incorporated into the early stages of technological development, so study results are often not reported. This review includes three studies on the effects of target group-specific interfaces. One of them included about 900 participants in a pre/post-design and identified positive results on overall and ICU mortality, length of stay and hospitalisation cost for a specific EMR-interface for ICU use. ${ }^{108}$ The other two studies report rather preliminary, but nonetheless positive results: an early user study on dashboard design for an EHR shows the potential of interface designs to improve efficiency and task accuracy, ${ }^{109}$ and a qualitative study on a specific interface for people with memory impairment or dementia demonstrates that interfaces aligned for people with dementia enable a beneficial use of Internet resources for this target group. ${ }^{110}$

\section{Robotic Technologies}

There are numerous different types of robots developed for and tested in care facilities or homes of persons in need of care. ${ }^{111-113}$ This review distinguishes between assistive social robots and assistive robots that do not perform social interaction with their users. The main function of these non-social assistive robots is physical assistance. They include simple service robots like robotic vacuum cleaners, but also robots for mobility enhancement such as robotic arms, robotic walkers or exoskeletons and autonomous transportation robots or robotic beds. Social assistive robots are differentiated according to the main function of the robot into therapeutic robots, telepresence robots, service robots and socially interactive robots.

This review includes 24 studies on robots. Most of them focus on therapeutic robots, predominantly on Paro, the robotic seal, which is the main focus in 16 out of the 18 studies on therapeutic robots. There is one study on a therapeutic robot cat (JustoCat) ${ }^{114}$ and one on the humanoid robot NAO. ${ }^{115}$ Two studies compare Paro to other robots, namely $\mathrm{NAO}^{116}$ and the robot dinosaur PLEO. ${ }^{117}$ Paro is thus the best investigated technology included in 
this review. Five of these studies are RCTs, but most of them are relatively small. ${ }^{11,12,118,119}$ There is only one RCT that included 138 participants. ${ }^{120}$ While all these studies yield positive results in social and psychological dimensions, they differ in detail. Some of them report positive results on depression scales, others cannot verify such effects but report positive results on agitation in people with dementia, loneliness, and well-being, especially in patients with severe dementia.

There are only very few studies on other types of social assistive robots. In one quasi-experimental study, a social service robot (Cafero) provided assistance by measuring patients' vital signs prior to personal consultations in a hospital, leading to significant reductions in consultation length, but effects on the patients were not assessed. ${ }^{121}$ A quasi-experiment on a telepresence robot accompanying nurses on night-rounds in ICUs found only small positive effects on satisfaction about care decisions of caregivers (not statistically significant). ${ }^{122}$ In another quasiexperiment on socially interactive robots that employed a guide robot and Cafero to provide entertainment, communication and health monitoring no significant effects either in patients or in caregivers were found, but a clear limitation of this study was that the robots were seldom used by patients. ${ }^{18}$

Three (low-level) studies focus on non-social assistive robots used for transport, physical assistance or mobility enhancement. One case study demonstrated positive time effects with pharmacy delivery robots in a hospital/ICU setting. ${ }^{123}$ A user study on a robotic patient lifter showed that the force needed to handle the lifter could be significantly reduced compared to a standard hoist. ${ }^{17}$ Another user study explored an electronic wheelchair that was equipped with an anti-collision sensor skirt. ${ }^{124}$ Though positive effects on independent mobility of long-term care residents with cognitive limitations were observed, the device did not provide the sensor reliability that would be necessary to navigate safely around other inhabitants.

This review also includes three systematic reviews on robots in nursing care. Two of them report results on studies on socially assistive robots in elderly care. ${ }^{1,113}$ Especially the study by Kachouie et al - covering the years from 2002 to 2012 - comprises a broader set of robots than is included in this study. ${ }^{113}$ Both of these systematic reviews conclude that the evidence reported in the studies is predominantly positive, but their methodological quality is mostly low, and the sample sizes small, so the generalizability of the results is very limited.
A review by Pearce et al focuses on robotic devices to enable older people to live at home. ${ }^{112}$ They identified four studies that present some kind of effectiveness results, but these are all user studies, predominantly situated in laboratory settings.

Though the field of robotic technology that is researched with respect to possible use in nursing care is extensive, research - with the exception of Paro - is still at a very early stage and no conclusive results in terms of effectiveness are available yet.

\section{Monitoring/Sensors}

Technical solutions that use different types of sensors to monitor patients and support caregiving have evolved into an important research area in recent years. Besides complex solutions with many different types of sensors - as in AAL settings - many applications have been developed that provide less complex solutions, using mostly only one kind of sensor - or have a very specific scope of application. Seventeen studies dealing with this specific kind of sensor application are included in this review, and 12 of them report positive results. Most of the studies aim at some kind of behaviour analysis - mostly to detect or prevent specific risks ${ }^{125-131}$ or to analyse behaviour patterns to support care decisions. ${ }^{132-134}$ Other application fields are vital sign monitoring, ${ }^{135-138}$ external risk detection ${ }^{139}$ and tracking or identification of persons. ${ }^{140,141}$

The most common application of sensors in this review is the analysis of behaviour for the prevention of falls. Two RCTs in hospital settings could not identify any reductions in fall rate per patient days, ${ }^{127,130}$ two quasi-experimental studies yield positive results, but one of them had to acknowledge study limitations that might question the results. $^{128,129}$ These results are in general confirmed by a systematic review on fall prevention technologies, which also identified positive results in quasiexperimental studies and no significant reductions in fall rates in RCTs. ${ }^{142}$

Positive results were achieved by an RCT using wearable patient sensors in an ICU setting to prevent pressure ulcers. ${ }^{125}$ Positive effects of monitoring devices for preventing pressure injuries are also supported by a systematic review that included nine studies (no RCTs) that all identified positive effects of sensor applications. These include studies on pressure sensing mats, pressure sensors built into mattresses, piezoelectric sensors placed under the mattress, and a portable skin monitor. ${ }^{143}$ 
Another RCT in the field of behaviour analysis yielded positive results for an intervention that used ambient sensors for older people living in assisted living communities to analyse behaviour patterns for early illness detection. ${ }^{133}$ A small quasi-experiment that used behaviour analysis for decision support in an outpatient long-term care setting observed no statistically significant changes in the clients but did identify positive effects on the informal caregivers (decrease in subjective burden and decrease in time spent on the client). ${ }^{132}$

Three studies used sensors for vital sign monitoring with positive results. One study worth highlighting is a large controlled clinical trial situated in an ICU that reported a positive effect on the average length of stay in the ICU and, as a secondary outcome, a lower number of cardiac arrest alarms. ${ }^{135}$

Monitoring/Sensors are one of the largest categories in this review. While positive results on fall prevention could not be substantiated by the RCTs, a large RCT on pressure ulcer prevention showed positive results. Nevertheless, there is a substantial number of quasi-experimental studies with positive results, on which future research can build.

\section{Assistive Devices}

In this review, assistive devices are defined as physical devices made to assist or support a caregiver or a person in need of care in performing a particular task that are enhanced with digital technology. These are especially devices that are digitally networked/connected or equipped with sensor technology. Particularly in hospital settings, the distinction between assistive devices and (primarily) medical technologies is challenging. The goal of this review was to focus on technologies or technological aspects that facilitate nursing care activities.

Empirical evidence in this technological area is still scarce. There are only seven studies on assistive devices included in this review. Three of the studies focus on electronic medication dispensing devices. An RCT that compared the effects of nurse-coordinated medication selfmanagement in an outpatient setting, either supported by a simple box with different compartments or by a medication dispensing machine, was unable to identify an additional benefit to be gained from the device, ${ }^{144}$ while one case and one user study at least found positive or ambivalent effects. ${ }^{145,146}$ Two studies report positive effects of smart pump technologies in hospital settings, ${ }^{147,148}$ a small RCT finds positive effects of a multimodal distraction device during acute burn care. ${ }^{149}$
The only device tested in an inpatient long-term care setting is a smart drink monitor device. The user study yielded positive results on drinking amount and frequency during a 1 week intervention phase. ${ }^{150}$

In the systematic reviews included in this review, evidence on assistive devices is also scant. Most of the reviews identified either no or only low-quality evidence on a small range of assistive devices. A study by van der Roest et al searched for studies on assistive technologies for memory support in dementia and was unable to identify a single high-level study. ${ }^{151}$ Fleming and Sum searched for assistive technology in the care of people with dementia and identified only few studies with very small samples focusing on memory support and alarm systems. $^{2}$

Overall, positive evidence in this research area is very limited, and mostly only supported by rather small or low evidence-level studies.

\section{Ambient Assisted Living Systems (AAL Systems)}

AAL systems are integrated multifunctional, often modular systems that support a person in his or her living environment. The application generally comprises a set of different technologies, often sensors and communication technologies, which intend to support the well-being, security and independent living of an elderly person.

Our search resulted in only three studies that tried to assess effects on persons in need of care or caregivers. The largest study - a quasi-experimental study on 59 inhabitants of an AAL supported assisted living facility in the intervention group - identified small positive effects on feelings of personal safety, but no effects on QoL or feelings of independence. ${ }^{14}$ A quasi-experimental study with 11 older people with dementia in the intervention group could not identify any significant differences in perceived autonomy, care needs, QoL or performance of daily activities. ${ }^{15}$ A qualitative study on 14 persons with dementia and their informal caregivers, however, reported positive effects on the sense of safety and security of the person with dementia perceived by the caregiver as well as positive effects on the caregiver with respect to anxieties, concerns and an increased time for restorative activities. ${ }^{16}$

\section{Virtual Reality}

All three studies on virtual reality devices included in this review focus on distraction and/or pain reduction during wound care in hospital settings. All three studies are rather small (with about 20 patients testing the intervention). One $\mathrm{RCT}^{152}$ and a quasi-experimental study ${ }^{153}$ report positive 
results with respect to medication needed, the RCT reports positive effects on pain (rated by nurses). The third study, a three-armed RCT, does not identify any differences in pain reduction for all three groups. ${ }^{154}$

\section{Settings and Target Groups}

Most of the studies in this scoping review are situated in formal care institutions, predominantly in hospitals. Hospitals, together with ICUs, account for more than $40 \%$ of all studies. The second largest setting, in almost $30 \%$ of all studies, is inpatient long-term care. By contrast, the proportion of studies situated in peoples' homes (12.6\%), outpatient long-term care $(8.7 \%)$ and cross-sectoral care $(3.1 \%)$ is quite low. Thus, a few studies were identified in settings in which people could be supported and hence avoid greater dependency on formal care (see Table 5).

Figure 2 shows the target groups of the technologies in the included studies (as some technologies target more than one target group, the sum is larger than the number of studies). About half of the studies focus on persons in need of care (51\%), with a large share of studies aiming at people with dementia (19\%). Forty-seven percent of all studies focus on formal caregivers. In comparison to this figure, the share of studies that focus on informal carers is quite small (8\%), about half of them target informal caregivers of persons with dementia. There are also few studies that focus mainly on the institution; these are almost exclusively studies on EHR/EMR and HIS. Robotic technologies so far mainly focus on persons in need of care rather than supporting carers. Specific apps are mainly developed or tested for people with dementia or their caregivers.

\section{Regional Research Focuses}

Research on digital technologies for nursing care is performed worldwide. The first authors of the 123 single studies come from 24 different countries. Still, there are some countries that are particularly active and have specific research interests. By far the most research was done in the US, and $38 \%$ of the studies have US first authors. A specific research focus in the US is on ICT, in particular EHR/EMR and HIS. Researchers from other countries seldom published research on these topics. Two-thirds of the studies were done in five countries only, besides the US, these are the UK, Netherlands, Australia and China. While UK and Chinese authors published especially on ICT in general, Australian authors focussed on robotic technologies. Canada, Japan, Germany, and Taiwan are represented with four studies each, all other countries
Table 5 Number of Studies by Setting

\begin{tabular}{|l|l|l|}
\hline Settings & Number of Studies & In Percent \\
\hline Hospital & 46 & 36.2 \\
ICU & 7 & 5.5 \\
Inpatient long-term care & 38 & 29.9 \\
Daycare centre & 3 & 2.4 \\
Outpatient long-term care & 11 & 8.7 \\
Home & 16 & 12.6 \\
Cross-sectoral care & 4 & 3.1 \\
Undefined & 2 & 1.6 \\
\hline
\end{tabular}

Notes: Four studies relate to two settings; thus, the sum is larger than 123 or $100 \%$.

show less first authors. New Zealand is strong with three studies on robotic technologies.

\section{Discussion}

\section{General Results}

Overall, the range of technologies that is researched in relation to supporting nursing care is quite extensive, but hardly any technology has been researched intensively enough to produce conclusive results. The number of studies with a high level of evidence is generally low.

Most studies included in this scoping review are concerned with ICT, the scope of applications is broad, but the number of RCTs is small. Other technology areas that are strongly represented in this review are robotic technologies and monitoring/sensor technologies. Within the robotics category, two-thirds of the studies and all RCTs focus on the robotic seal Paro, so this is one of the few technologies that is quite extensively researched; nevertheless, most of the studies are rather small. ${ }^{11,12,118,119,155}$ In the monitoring/ sensors category, there are only four RCTs, of which only two report positive results, one on pressure ulcer prevention, ${ }^{125}$ the other on behaviour analysis for care decision support. ${ }^{133}$ Still there are several quasiexperimental studies, most of which yield positive results, which may point to promising future research areas. Other scoping reviews on monitoring or sensor applications that also include studies on technical effectiveness show that research in this field is very active. ${ }^{30,156} \mathrm{~A}$ recent scoping review on sensor applications to detect falls found 10 different types of sensor systems in 118 studies on supporting fall detection. ${ }^{156}$ Most of them had only technological outcomes and the technology readiness level was often low. Nonetheless, this shows that there is a potential for future applications as soon as their reliability improves. 


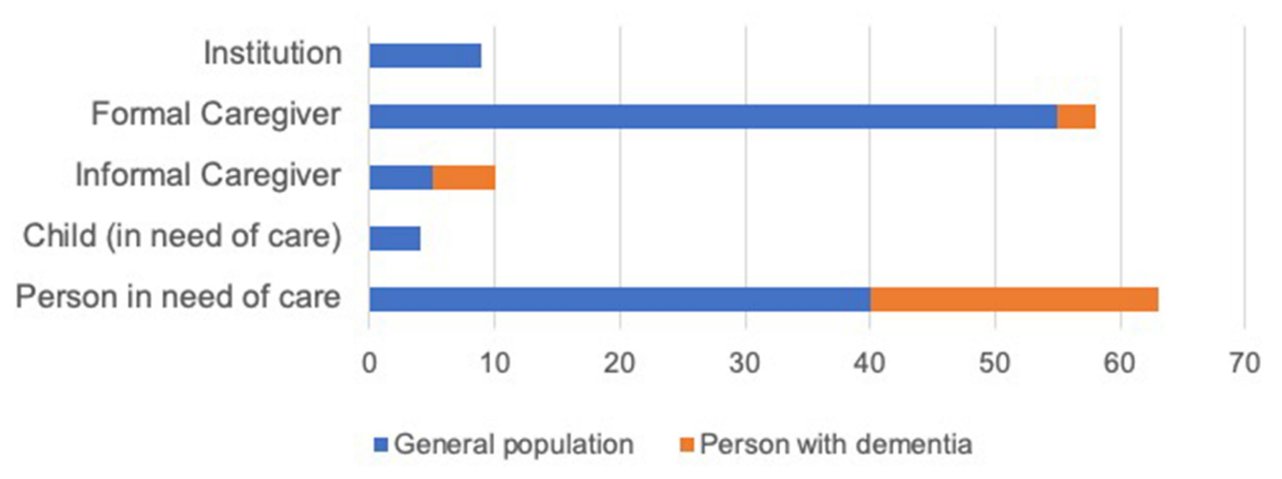

Figure 2 Number of studies by target group.

In general, the quality of studies included in this scoping review - in terms of their evidence level - is quite low; thus, the generalizability of the results that are presented is limited. This general result is in line with the resumés of many of the systematic reviews included. Most of them conclude that the quality of the included studies was poor to moderate, reported outcomes were often heterogeneous, and the generalizability of the results therefore very limited. ${ }^{1,4,23,25,92,93,112,113,157}$ So, while many of these systematic reviews reach further back in time than this study, it can be concluded from this assessment of the literature, that this basic problem has not changed in recent years. One exception is the area of computerized decision support: a systematic review by Bright et al included 148 RCTs ${ }^{66}$ and a meta-analysis by Roshanov et al covered $162 \mathrm{RCTs},{ }^{68}$ so the evidence base on this kind of system is rather good. Nonetheless, most of the included studies refer rather to medical care, and the number of studies included that refer specifically to nursing care remains unclear.

\section{Settings and Target Groups}

There are high expectations that digital technologies may help to maintain the independence of people in need of care and support formal and informal caregivers. ${ }^{1-3,158}$ Research on technology in care is often promoted as part of a strategy to reduce the rapidly rising demands for skilled workers in nursing care in many industrial countries induced by demographic changes. ${ }^{158}$ Given these concerns, it is remarkable that, to date, most studies on technological care support focus on hospital and inpatient long-term care settings. Only very few studies focus on outpatient long-term care or home settings, as this review shows. In particular, cross-sectoral care support is largely unexplored. This could be due to the fact that it is much easier to conduct scientific research studies in inpatient settings. However, if digital technologies are to play a role in reducing the need for professional care support, it will be essential to support those in need of care so that they can stay in their home environments, as many of them wish to do. ${ }^{159}$ Of course, it is also necessary to promote research that relieves care professionals in hospitals and inpatient long-term care facilities. However, a stronger focus than hitherto should be placed on research on technological care support that may delay the need for professional care or support outpatient care arrangements. ${ }^{30}$ The small number of studies that focus on support for informal carers points in the same direction. As only few studies focus on informal caregivers so far, there may be an as yet unexplored potential to integrate them even better into formal care processes, or reduce their care burden. ${ }^{30}$

\section{Direction of Study Results and Publication Bias}

The large majority of studies included in this review (74\%) reports positive results. There are also ambivalent results, but none of the studies reports purely negative effects of the technologies in question. This is a clear indication that there is a distinctive publication bias. It must be assumed that negative results are reported less frequently, as has already been reported in other studies, such as, for example, a study on clinical trials on EHR. ${ }^{160}$ It should also be pointed out that the higher the evidence level of the respective study, the lower the number of positive results. This may also indicate that positive effects in low evidence-level studies may not be replicable in studies with higher evidence levels. The studies on medication dispensing systems, sensor-based monitoring systems for fall prevention and AAL are examples of technological applications that show positive results in the low-level studies 
included, but only neutral results in the respective RCTs. ${ }^{15,127,130,144}$ This clearly demonstrates that positive effects of low evidence level studies have to be assessed with caution. Nevertheless, they provide valuable information on technologies that should be further explored.

We do not report effect sizes in this review, but overall, the generated effects are often relatively small, with especially high-quality studies showing predominantly rather small effects.

While RCTs are still the gold standard for effectiveness research, RCTs also pose major challenges for effectiveness research on digital technological innovations. ${ }^{161}$ A particularly significant problem is the high time requirement for study preparation and execution. Many years elapse between grant application and the analysis of results. Due to further technological developments, the tested innovations may already be outdated by more recent technologies by the time a result is published. ${ }^{162}$ The development of more rapid research methods or processes is essential to produce more timely and still reliable results. ${ }^{158,163}$

The results of the mixed methods studies are particularly interesting. ${ }^{24,38,72,78,90}$ These have a large number of ambivalent results; ie, negative results are reported next to positive or neutral results. This indicates that the effects of technologies may be multi-layered, especially as they are often part of quite complex care interventions. Mixed methods studies may have the capacity to reveal opposing results for different target groups. Negative effects on specific aspects of the technology may not be discovered if only the effects on a single target group by a single method are analysed. Technological innovations may have complex effects, eg, on care work processes, that will only be captured if this complexity is also taken into account methodically. ${ }^{164}$ Ambivalent results may generally provide interesting indications of the conditions under which the use of a technology can be successful - and suggest which negative effects should be avoided in the further development of a technology.

As the study by Angst et al on HIS has shown, the extent of IT implementation may have differentiated effects. ${ }^{37}$ This clearly indicates that the implementation of complex IT systems has to be done with care and under consideration of specific work processes so as to avoid unwanted negative effects. Similarily, some neutral or ambivalent results on EHR/EMR show that the technology has to be well adapted to the needs of the caregivers. More negative results tend to occur when EMR-based documentation is not well integrated in work processes and requires additional documentation efforts. ${ }^{54,58}$ Analysis of differences between successful and less successful interventions - as, eg, in the case of the many neutral or ambivalent telecare interventions - may be a promising approach to further develop some of the technical applications with ambivalent results.

Some research areas such as, for example, HIS and EHR/EMR, have strong regional research foci. Research results that are only obtained in one country may not be applicable to situations in other countries - still, the studies demonstrate the capability of such systems to affect patient safety indicators, for example, or even mortality rates.

\section{Strengths and Limitations of This Study}

To our knowledge, this is the first scoping review which maps such a wide range of digital technological interventions that are currently being researched in the field of nursing care with respect to effectiveness outcomes relating to people in need of care, caregivers and organizations. A wide range of technological search terms was included in the search strategy. Nevertheless, technologies that were not addressed explicitly during the extensive search may be underrepresented in our study sample. This may concern categories or technologies from EHR/EMR to telecare or barcode medication administration. It is also possible that specific assistive devices have been neglected because they have not been explicitly named as a search term. However, we expect the risk of bias to be relatively small, as we did not find any systematic reviews on the large categories such as EHR/EMR or Telecare that contradict our results. With respect to assistive devices, we were able to ascertain that none of the systematic reviews included refers to any relevant effectiveness-related results on an assistive device that was not included in this review. We should also point out that we did not include keywords such as information and communication in the search because the number of hits would not have been manageable. For these reasons, the diverse range of applications in the ICT sector may be underrepresented as well.

\section{Conclusion}

This scoping review provides a broad overview on the technological areas and technological solutions that were researched in recent years with respect to benefits for people in need of care, caregivers or organizations. Furthermore, the review shows the evidence levels at 
which the studies were carried out and confirms that for most technology areas high-quality studies are still missing.

Results on HIS or EHR/EMR show that there can be significant gains in effectiveness from digital technologies, but whether these effects occur also depends on the mode and specific context in which they are introduced. If, for example, nurses do not feel comfortable with the system, there is a high probability that potential benefits will not be achieved.

For many technologies, there is only very little evidence on positive effects so far. It is therefore not surprising that care institutions are reluctant to integrate innovative technological solutions into practice. This scoping review identifies a range of technologies that might be worth investigating with high-quality studies.

In regard to the frequently stated objective of relieving caregivers, and offsetting the shortage of nursing care professionals, there are surprisingly few studies that manage to show corresponding results. But it is reassuring that there are so many studies aiming to improve the quality of care or positive benefits for those in need of care. Research on informal care arrangements and research on technological solutions that enable older people to remain at home (with a limited level of professional support) - ie, research focussing on outpatient long-term care and informal caregivers in particular - should be promoted more strongly. Research supporting cross-sectoral care is also very scarce so far.

Finally, there is a need for more high-quality studies to support the evidence of the effectiveness of digital technologies for nursing care, but at the same time, it will be necessary to develop more rapid research methods that still do justice to the degree of complexity required and maintain high-quality standards.

\section{Abbreviations}

AAL, ambient assisted living; CDSS, computerized decision support system; CPOE, computerized physician order entry; EHR, electronic health record; EMR, electronic medical record; HIS, hospital/care institution information system; ICT, information and communication technologies; ICU, intensive care unit; IT, information technology; QoL, quality of life; RCT, randomized controlled trial; US, United States (of America).

\section{Author Contributions}

All authors conceived the study. KH, TK and DD shared work in all stages of the screening process. KH and TK performed the data extraction for the single studies, $\mathrm{KH}$ performed the data extraction for the reviews, interpreted the results and wrote the first draft of the manuscript. HR and KWO obtained funding for the study. All authors contributed to data analysis, drafting or revising the article, have agreed on the journal to which the article will be submitted, gave final approval of the version to be published, and agree to be accountable for all aspects of the work.

\section{Funding}

This study received funding from the German Federal Ministry of Education and Research (BMBF) (Grant number: 16SV7821) within the project "Pflegeinnovationszentrum" (PIZ). The BMBF was not actively involved in the design of the study, the data collection, the analysis, the interpretation of the data or in writing the manuscript. The authors are solely responsible for the results.

\section{Disclosure}

Kai Huter reports grants from German Federal Ministry of Education and Research, during the conduct of the study. The authors report no other potential conflicts of interest in this work.

\section{References}

1. Bemelmans R, Gelderblom GJ, Jonker P, de Witte L. Socially assistive robots in elderly care: a systematic review into effects and effectiveness. J Am Med Dir Assoc. 2012;13(2):114-120.e111. doi:10.1016/j.jamda.2010.10.002

2. Fleming R, Sum S. Empirical studies on the effectiveness of assistive technology in the care of people with dementia: a systematic review. J Assistive Technol. 2014;8(1):14-34. doi:10.1108/JAT-09-2012-0021

3. Liu L, Stroulia E, Nikolaidis I, Miguel-Cruz A, Rios Rincon A. Smart homes and home health monitoring technologies for older adults: a systematic review. Int J Med Inform. 2016;91:44-59. doi:10.1016/j. ijmedinf.2016.04.007

4. Khosravi P, Ghapanchi AH. Investigating the effectiveness of technologies applied to assist seniors: a systematic literature review. Int $J$ Med Inform. 2016;85(1):17-26. doi:10.1016/j.ijmedinf.2015.05.014

5. CEDEFOP. Briefing Note: Skill Shortage and Surplus Occupations in Europe. Thessaloniki; 2016.

6. Greenhalgh T, Wherton J, Papoutsi C, et al. Beyond adoption: a new framework for theorizing and evaluating nonadoption, abandonment, and challenges to the scale-up, spread, and sustainability of health and care technologies. J Med Internet Res. 2017;19(11):e367. doi:10.2196/ jmir.8775

7. Krick T, Huter K, Seibert K, Domhoff D, Wolf-Ostermann K. Measuring the effectiveness of digital nursing technologies: development of a comprehensive digital nursing technology outcome framework based on a scoping review. BMC Health Serv Res. 2020;20 (1):243. doi:10.1186/s12913-020-05106-8

8. Rouleau G, Gagnon MP, Côté J, Payne-Gagnon J, Hudson E, Dubois CA. Impact of information and communication technologies on nursing care: results of an overview of systematic reviews. $J$ Med Internet Res. 2017;19(4):e122. doi:10.2196/jmir.6686 
9. Billings J, Carretero Gomez S, Kagialaris G, Mastroyiannakis T, MerilÄInen-Porras S. The role of information technology in long term care for older people. In: Le A, editor. Long-Term Care in Europe. Palgrave Macmillan; 2013:252-277.

10. Damant J, Knapp M, Freddolino P, Lombard D. Effects of digital engagement on the quality of life of older people. Health Soc Care Community. 2017;25(6):1679-1703. doi:10.1111/hsc.12335

11. Robinson H, MacDonald B, Kerse N, Broadbent E. The psychosocial effects of a companion robot: a randomized controlled trial. $\mathrm{J} \mathrm{Am} \mathrm{Med}$ Dir Assoc. 2013;14(9):661-667. doi:10.1016/j.jamda.2013.02.007

12. Joranson N, Pedersen I, Rokstad AM, Ihlebaek C. Change in quality of life in older people with dementia participating in Paro-activity: a cluster-randomized controlled trial. $J$ Adv Nurs. 2016;72(12):3020-3033. doi:10.1111/jan.13076

13. Haux R, Hein A, Kolb G, et al. Information and communication technologies for promoting and sustaining quality of life, health and self-sufficiency in ageing societies-outcomes of the lower saxony research network design of environments for ageing (GAL). Inform Health Soc Care. 2014;39(3-4):166-187. doi:10.3109/17538157.2014.931849

14. Trukeschitz B, Schneider C., Ring-Dimitriou S. Smartes Betreutes Wohnen: Nutzung, Systemakzeptanz und Wirkungen von "meinZentrAAL "[Smart assisted living: usage, system acceptance and effects of "myCentrAAL"].BoD Books on Demand. Norderstedt; 2018.

15. Hattink BJJ, Meiland FJM, Overmars-Marx T, et al. The electronic, personalizable Rosetta system for dementia care: exploring the user-friendliness, usefulness and impact. Disabil Rehabil Assist Technol. 2016;11(1):61-71.

16. Nijhof N, van Gemert-pijnen LJ, Woolrych R, Sixsmith A. An evaluation of preventive sensor technology for dementia care. $J$ Telemed Telecare. 2013;19(2):95-100. doi:10.1258/jtt.2012.120605

17. Ranasinghe R, Dantanarayana L, Tran A, Lie S, Behrens M, Liu L Smart hoist: an assistive robot to aid carers. Paper presented at: 2014 13th International Conference on Control Automation Robotics \& Vision (ICARCV); December 10-12, 2014; 2014.

18. Broadbent E, Kerse N, Peri K, et al. Benefits and problems of health-care robots in aged care settings: a comparison trial. Australas J Ageing. 2016;35(1):23-29. doi:10.1111/ajag.12190

19. Hu C, Kung S, Rummans TA, Clark MM, Lapid MI. Reducing caregiver stress with internet-based interventions: a systematic review of open-label and randomized controlled trials. J Am Med Inform Assoc. 2015;22(e1):e194 e209. doi:10.1136/amiajnl-2014-002817

20. Madara Marasinghe K. Assistive technologies in reducing caregiver burden among informal caregivers of older adults: a systematic review. Disabil Rehabil Assist Technol. 2016;11(5):353-360.

21. Tixier M, Lewkowicz M Looking for respite and support: technological opportunities for spousal caregivers. Paper presented at: Proceedings of the 33rd Annual ACM Conference on Human Factors in Computing Systems; 2015; New York, NY, USA.

22. Lee E. Do technology-based support groups reduce care burden among dementia caregivers? A review. J Evid Inf Soc Work. 2015;12(5):474-487. doi:10.1080/15433714.2014.930362

23. Davies A, Rixon L, Newman S. Systematic review of the effects of telecare provided for a person with social care needs on outcomes for their informal carers. Health Soc Care Community. 2013;21(6):582-597.

24. Pare G, Sicotte C, Moreault MP, Poba-Nzaou P, Templier M, Nahas G Effects of mobile computing on the quality of homecare nursing practice. Paper presented at: 2011 44th Hawaii International Conference on System Sciences; January 4-7, 2011; 2011.

25. Reis ZSN, Maia TA, Marcolino MS, Becerra-Posada F, NovilloOrtiz D, Ribeiro ALP. Is there evidence of cost benefits of electronic medical records, standards, or interoperability in hospital information systems? Overview of systematic reviews. JMIR Med Inf. 2017;5(3):e26. doi:10.2196/medinform.7400
26. Meißner A, Schnepp W. Staff experiences within the implementation of computer-based nursing records in residential aged care facilities: a systematic review and synthesis of qualitative research. BMC Med Inform Decis Mak. 2014;14(1). doi:10.1186/1472-6947-14-54

27. Appari A, Johnson EM, Anthony DL. Information technology and hospital patient safety: a cross-sectional study of US acute care hospitals. Am J Manag Care. 2014;20(17):eSP39-eSP47.

28. Yeaman B, Ko KJ, Castillo R. Care transitions in long-term care and acute care: health information exchange and readmission rates. Online J Issues Nurs. 2015;20(3):1.

29. Meyer-Delpho C, Schubert HJ. Potential of information and communications technology to improve intersectoral processes of care: a case study of the specialised outpatient palliative care. Gesundheitswesen. 2014;77(8-9):550-556.

30. Krick T, Huter K, Domhoff D, Schmidt A, Rothgang H, WolfOstermann K. Digital technology and nursing care: a scoping review on acceptance, effectiveness and efficiency studies of informal and formal care technologies. BMC Health Serv Res. 2019;19(1):400. doi:10.1186/s12913-019-4238-3

31. Arksey H, O'Malley L. Scoping studies: towards a methodological framework. Int J Soc Res Methodol. 2005;8 (1):19-32. doi:10.1080/1364557032000119616

32. Levac D, Colquhoun H, O'Brien KK. Scoping studies: advancing the methodology. Implement Sci. 2010;5(1):69. doi:10.1186/17485908-5-69

33. Ackley BJ. Evidence-Based Nursing Care Guidelines: MedicalSurgical Interventions. Elsevier Health Sciences; 2008.

34. Concato J. Observational versus experimental studies: what's the evidence for a hierarchy? NeuroRx. 2004;1(3):341-347. doi:10.1602/neurorx.1.3.341

35. Restuccia JD, Cohen AB, Horwitt JN, Shwartz M. Hospital implementation of health information technology and quality of care: are they related? BMC Med Inform Decis Mak. 2012;12(1). doi:10.1186/1472-6947-12-109

36. McKenna RM, Dwyer D, Rizzo JA. Is HIT a hit? The impact of health information technology on inpatient hospital outcomes. Appl Econ. 2017:1-13.

37. Angst CM, Devaraj S, D'Arcy J. Dual role of IT-assisted communication in patient care: a validated structure-process-outcome framework. Manag Inf Syst. 2012;29(2):257-292. doi:10.2753/ MIS0742-1222290209

38. Alexander GL, Pasupathy KS, Steege LM, Strecker EB, Carley KM. Multi-disciplinary communication networks for skin risk assessment in nursing homes with high IT sophistication. Int J Med Inform. 2014;83(8):581-591. doi:10.1016/j.ijmedinf.2014.05.001

39. Alexander GL, Steege LM, Pasupathy KS, Wise K. Case studies of IT sophistication in nursing homes: a mixed method approach to examine communication strategies about pressure ulcer prevention practices. Int $J$ Ind Ergon. 2015;49:156-166. doi:10.1016/j.ergon.2012.12.002

40. Munyisia EN, Yu P, Hailey D. The impact of an electronic nursing documentation system on efficiency of documentation by caregivers in a residential aged care facility. J Clin Nurs. 2012;21(19/ 20):2940-2948. doi:10.1111/j.1365-2702.2012.04157.x

41. Steurbaut K, Colpaert K, Van Hoecke S, et al. Design and evaluation of a service oriented architecture for paperless ICU tarification. J Med Syst. 2012;36(3):1403-1416. doi:10.1007/ s10916-010-9602-0

42. Patmon FL, Gee PM, Rylee TL, Readdy NL. Using interactive patient engagement technology in clinical practice: a qualitative assessment of nurses' perceptions. J Med Internet Res. 2016;18 (11):e298. doi:10.2196/jmir.5667

43. Mitchell S, Yaylacicegi U. EHR prescription for small, medium, and large hospitals: an exploratory study of Texas acute care hospitals. Int J Electron Healthc. 2012;7(2):125-140. doi:10. 1504/IJEH.2012.049874 
44. Bradley SL. A Phenomenological Exploration of Nurses' Perceptions of the Effect of Electronic Documentation on Healing Relationships. University of Phoenix; 2011.

45. Takian A, Sheikh A, Barber N. We are bitter, but we are better off: case study of the implementation of an electronic health record system into a mental health hospital in England. BMC Health Serv Res. 2012;12(1). doi:10.1186/1472-6963-12-484

46. Yusof MM. A case study evaluation of a critical care information system adoption using the socio-technical and fit approach. Int $J$ Med Inform. 2015;84(7):486-499. doi:10.1016/j. ijmedinf.2015.03.001

47. Seibert HH, Maddox RR, Flynn EA, Williams CK. Effect of barcode technology with electronic medication administration record on medication accuracy rates. Am J Health Syst Pharm. 2014;71(3):209-218. doi:10.2146/ajhp130332

48. Appari A, Carian EK, Johnson ME, Anthony DL. Medication administration quality and health information technology: a national study of US hospitals. J Am Med Inform Assoc. 2012;19(3):360-367. doi:10.1136/amiajnl-2011-000289

49. Chanyagorn P, Kungwannarongkun B, Chanyagorn W Design of electronic nursing Kardex system for medication error prevention in IPD patients. Paper presented at: 2016 6th IEEE International Conference on Control System, Computing and Engineering (ICCSCE); November 25-27, 2016; 2016.

50. Ching JM, Williams BL, Idemoto LM, Blackmore CC. Using lean 'automation with a human touch' to improve medication safety: a step closer to the 'perfect dose'. Jt Comm J Qual Patient Saf. 2014;40(8):341-350. doi:10.1016/S1553-7250(14)40045-X

51. Huang H-Y, Lee -T-T. Impact of bar-code medication administration on nursing activity patterns and usage experience in Taiwan. CIN. 2011;29(10):554-563.

52. Oakley B, Hunter JB. Implementing an electronic patient handover system. Br J Hosp Med. 2017;78(1):16-19. doi:10.12968/ hmed.2017.78.1.16

53. Clarke CN, Patel SH, Day RW, et al. Implementation of a standardized electronic tool improves compliance, accuracy, and efficiency of trainee-to-trainee patient care handoffs after complex general surgical oncology procedures. Surgery. 2017;161(3):869-875.

54. Lear CL, Walters C. Use of electronic nurse reminders to improve documentation. CIN. 2015;33(12):523-529.

55. Paranilam SO. Effectiveness of an Electronic Pain Notification System on Postoperative Pain. Baltimore: University of Maryland; 2013.

56. Hitt LM, Tambe P. Health care information technology, work organization, and nursing home performance. Ind Labor Relat Rev. 2016;69(4):834-859. doi:10.1177/0019793916640493

57. Meehan R. Electronic health records in long-term care: staff perspectives. J Appl Gerontol. 2017;36(10):1175-1196. doi:10.1177/0733464815608493

58. Rantz MJ, Alexander G, Galambos C, et al. The use of bedside electronic medical record to improve quality of care in nursing facilities: a qualitative analysis. CIN. 2011;29(3):149-156.

59. McKibbon KA, Lokker C, Handler SM, et al. Enabling medication management through health information technology (Health IT). Evid Rep Technol Assess (Full Rep). 2011;201:1-951.

60. McKibbon KA, Lokker C, Handler SM, et al. The effectiveness of integrated health information technologies across the phases of medication management: a systematic review of randomized controlled trials. J Am Med Inform Assoc. 2012;19(1):22-30. doi:10.1136/amiajnl-2011-000304

61. Blum D, Raj SX, Oberholzer R, Riphagen II, Strasser F, Kaasa S. Computer-based clinical decision support systems and patient-reported outcomes: a systematic review. Patient. 2015;8 (5):397-409. doi:10.1007/s40271-014-0100-1
62. Lapane KL, Hughes CM, Daiello LA, Cameron KA, Feinberg J. Effect of a pharmacist-led multicomponent intervention focusing on the medication monitoring phase to prevent potential adverse drug events in nursing homes. $J \mathrm{Am}$ Geriatr Soc. 2011;59(7):1238-1245. doi:10.1111/j.15325415.2011.03418. $\mathrm{x}$

63. Dykes PC, I-Ching EH, Soukup JR, Chang F, Lipsitz S. A case control study to improve accuracy of an electronic fall prevention toolkit. AMIA Annual Symposium proceedings/AMIA Symposium AMIA Symposium; 2012:170-179.

64. Lang RLN. Evaluating the Effectiveness of Nurse-Focused Computerized Clinical Decision Support on Urinary Catheter Practice Guidelines. Gardner-Webb University; 2012.

65. Salinas J, Chung KK, Mann EA, et al. Computerized decision support system improves fluid resuscitation following severe burns: an original study. Crit Care Med. 2011;39(9):2031-2038. doi:10.1097/CCM.0b013e31821cb790

66. Bright TJ, Wong A, Dhurjati R, et al. Effect of clinical decision-support systems: a systematic review. Ann Intern Med. 2012;157(1):29-43. doi:10.7326/0003-4819-157-1-201207030-00450

67. Lobach D, Sanders GD, Bright TJ, et al. Enabling health care decisionmaking through clinical decision support and knowledge management. Evid Rep Technol Assess (Full Rep). 2012;203:1-784.

68. Roshanov PS, Fernandes N, Wilczynski JM, et al. Features of effective computerised clinical decision support systems: meta-regression of 162 randomised trials. BMJ. 2013;346:7899.

69. Bowles KH, Hanlon AL, Glick HA, et al. Clinical effectiveness, access to, and satisfaction with care using a telehomecare substitution intervention: a randomized controlled trial. Int J Telemed Appl. 2011;2011:540138. doi:10.1155/2011/540138

70. Paré G, Poba-Nzaou P, Sicotte C. Home telemonitoring for chronic disease management: an economic assessment. Int J Technol Assess Health Care. 2013;29(2):155-161. doi:10.1017/S0266462313000111

71. Göransson C, Eriksson I, Ziegert K, et al. Testing an app for reporting health concerns-Experiences from older people and home care nurses. Int J Older People Nurs. 2017.

72. Cady RG, Finkelstein SM. Task-technology fit of video telehealth for nurses in an outpatient clinic setting. Telemed $J$ e-Health. 2014;20(7):633-639. doi:10.1089/tmj.2013.0242

73. Steventon A, Bardsley M, Billings J, et al. Effect of telecare on use of health and social care services: findings from the whole systems demonstrator cluster randomised trial. Age Ageing. 2013;42(4):501-508. doi:10.1093/ageing/aft008

74. Wakefield BJ, Vaughan-Sarrazin M. Home telehealth and caregiving appraisal in chronic illness. Telemed e-Health. 2017;23 (4):282-289. doi:10.1089/tmj.2016.0105

75. van der Heide LA, Willems CG, Spreeuwenberg MD, Rietman J, de Witte LP. Implementation of CareTV in care for the elderly: the effects on feelings of loneliness and safety and future challenges. Technol Disabil. 2012;24(4):283-291. doi:10.3233/TAD-120359

76. Chiang KF, Wang HH. Nurses' experiences of using a smart mobile device application to assist home care for patients with chronic disease: a qualitative study. J Clin Nurs. 2016;25(13-14):2008-2017. doi:10.1111/jocn.13231

77. Hicken BL, Daniel C, Luptak M, Grant M, Kilian S, Rupper RW. Supporting caregivers of rural veterans electronically (SCORE). J Rural Health. 2017;33(3):305-313. doi:10.1111/jrh.12195

78. Cady RG. Measuring the Impact of Technology on Nurse Workflow: A Mixed Methods Approach. University of Minnesota; 2012.

79. Capurro D, Ganzinger M, Perez-Lu J, Knaup P. Effectiveness of eHealth interventions and information needs in palliative care: a systematic literature review. J Med Internet Res. 2014;16(3): e72. doi:10.2196/jmir.2812 
80. Oliver DP, Demiris G, Wittenberg-Lyles E, Washington K, Day T, Novak H. A systematic review of the evidence base for telehospice. Telemed J E Health. 2012;18(1):38-47. doi:10.1089/tmj.2011.0061

81. Karlsen C, Ludvigsen MS, Moe CE, Haraldstad K, Thygesen E. Experiences of community-dwelling older adults with the use of telecare in home care services: a qualitative systematic review. JBI Database System Rev Implement Rep. 2017;15 (12):2913-2980. doi:10.11124/JBISRIR-2017-003345

82. Chuang ST, Liu YF, Fu ZX, et al. Application of a smartphone nurse call system for nursing care. Telemed $J$ e-Health. 2015;21 (2):105-109. doi:10.1089/tmj.2014.0071

83. Pemmassani V, Paget T, van Woerden HC, Pemmasani S. Handsfree communication to free up nursing time. Nurs Times. 2014;110(13):12-14.

84. Tielbur BR, Rice Cella DE, Currie A, et al. Discharge huddle outfitted with mobile technology improves efficiency of transitioning stroke patients into follow-up care. Am J Med Qual. 2015;30(1):36-44. doi:10.1177/1062860613510964

85. White C, McIlfatrick S, Dunwoody L, Watson M. Supporting and improving community health services-a prospective evaluation of ECHO technology in community palliative care nursing teams. BMJ Support Palliat Care. 2015.

86. Blakey JD, Guy D, Simpson C, et al. Multimodal observational assessment of quality and productivity benefits from the implementation of wireless technology for out of hours working. $B M J$ Open. 2012;2(2):e000701. doi:10.1136/bmjopen-2011-000701

87. Melby L, Brattheim BJ, Hellesø R. Patients in transition - improving hospital-home care collaboration through electronic messaging: providers' perspectives. J Clin Nurs. 2015;24(23/ 24):3389-3399. doi:10.1111/jocn.12991

88. Rodriguez CS, Rowe M, Thomas L, Shuster J, Koeppel B, Cairns P. Enhancing the communication of suddenly speechless critical care patients. Am J Crit Care. 2016;25(3):e40-e47. doi:10.4037/ajcc2016217

89. Wieck M, Blake B, Sellick C, et al. Utilizing technology to improve intraoperative family communication. Am $J$ Surg. 2017;213:895-900. doi:10.1016/j.amjsurg.2017.03.014

90. Wu R, Rossos P, Quan S, et al. An evaluation of the use of smartphones to communicate between clinicians: a mixed-methods study. J Med Internet Res. 2011;13(3):e59. doi:10.2196/jmir.1655

91. Arditi C, Rège-Walther M, Wyatt JC, Durieux P, Burnand B. Computer-generated reminders delivered on paper to healthcare professionals; effects on professional practice and health care outcomes. Cochrane Database Syst Rev. 2012;12:N.PAG-N.PAG.

92. Bhattarai P, Phillips J. The role of digital health technologies in management of pain in older people: an integrative review. Arch Gerontol Geriatr. 2017;68:14-24. doi:10.1016/j.archger.2016.08.008

93. Mickan S, Atherton H, Roberts NW, Heneghan C, Tilson JK. Use of handheld computers in clinical practice: a systematic review. BMC Med Inform Decis Mak. 2014;14(1).

94. Fagerström C, Tuvesson H, Axelsson L, Nilsson L. The role of ICT in nursing practice: an integrative literature review of the Swedish context. Scand J Caring Sci. 2017;31(3):434-448. doi: $10.1111 / \mathrm{scs} .12370$

95. Valerie T, Choy KL, Siu PKY, Lam HY, Ho GTS, Cheng SWY An intelligent performance assessment system for enhancing the service quality of home care nursing staff in the healthcare industry. Paper presented at: 2016 Portland International Conference on Management of Engineering and Technology (PICMET); September 4-8, 2016; 2016.

96. Zaccarelli C, Cirillo G, Passuti S, Annicchiarico R, Barban F Computer-based cognitive intervention for dementia Sociable: motivating platform for elderly networking, mental reinforcement and social interaction. Paper presented at: 2013 7th International Conference on Pervasive Computing Technologies for Healthcare and Workshops; May 5-8, 2013; 2013.
97. Zhuang J, Fang R, Feng X, et al. The impact of human-computer interaction-based comprehensive training on the cognitive functions of cognitive impairment elderly individuals in a nursing home. J Alzheimers Dis. 2013;36(2):245-251. doi:10.3233/JAD-130158

98. Berenbaum R, Lange Y, Abramowitz L Augmentative alternative communication for Alzheimer's patients and families? Using SAVION. Paper presented at: Proceedings of the 4th International Conference on PErvasive Technologies Related to Assistive Environments; 2011; New York, NY, USA.

99. Nordheim J, Hamm S, Kuhlmey A, Suhr R. Tablet computers and their benefits for nursing home residents with dementia: results of a qualitative pilot study. Z Gerontol Geriatr. 2015;48(6):543-549. doi:10.1007/s00391-014-0832-5

100. Chen ST, Huang YGL, Chiang IT Using somatosensory video games to promote quality of life for the elderly with disabilities. Paper presented at: 2012 IEEE Fourth International Conference On Digital Game And Intelligent Toy Enhanced Learning; March 27-30, 2012; 2012.

101. Portela FR, Correia RJC, Fonseca JA, Andrade JM Wiitherapy on seniors - effects on physical and metal domains. Paper presented at: 2011 IEEE 1st International Conference on Serious Games and Applications for Health (SeGAH); November 16-18, 2011; 2011.

102. Mierlo L, Meiland F, Ven P, Hout H, Dröes R. Evaluation of DEM-DISC, customized e-advice on health and social support services for informal carers and case managers of people with dementia; a cluster randomized trial. Int Psychogeriatr. 2015;27 (8):1365-1378. doi:10.1017/S1041610215000423

103. Nijhof N, van Gemert-pijnen JEWC, Burns CM, Seydel ER. A personal assistant for dementia to stay at home safe at reduced cost. Gerontechnology. 2013;11(3):469-479. doi:10.4017/gt.2013.11.3.005.00

104. Webster G, Hanson VL. Technology for supporting care staff in residential homes. ACM Trans Access Comput. 2014;5(3):1-8. doi:10.1145/2543577

105. Yi-Sheng C, Hsin-Ju L, Yuan-Hsiang L Using wireless measuring devices and Tablet PC to improve the efficiency of vital signs data collection in hospital. Paper presented at: 2014 IEEE International Symposium on Bioelectronics and Bioinformatics (IEEE ISBB 2014); April 11-14, 2014; 2014.

106. Florczak B, Scheurich A, Croghan J, et al. An observational study to assess an electronic point-of-care wound documentation and reporting system regarding user satisfaction and potential for improved care. Ostomy Wound Manag. 2012;58(3):46-51.

107. Vowden K, Vowden P. A pilot study on the potential of remote support to enhance wound care for nursing-home patients. $J$ Wound Care. 2013;22(9):481-488. doi:10.12968/jowc.2013.22.9.481

108. Olchanski N, Dziadzko MA, Tiong IC, et al. Can a novel ICU data display positively affect patient outcomes and save lives? J Med Syst. 2017;41(11). doi:10.1007/s10916-017-0810-8.

109. Schall MC, Cullen L, Pennathur P, Chen H, Burrell K, Matthews G. Usability evaluation and implementation of a health information technology dashboard of evidence-based quality indicators. CIN. 2017;35(6):281-287.

110. Lazar A, Demiris G, Thompson HJ. Evaluation of a multifunctional technology system in a memory care unit: opportunities for innovation in dementia care. Inform Health Soc Care. 2016;41(4):373-386. doi:10.3109/17538157.2015.1064428

111. Robinson H, MacDonald B, Broadbent E. The role of healthcare robots for older people at home: a review. Int J Soc Rob. 2014;6 (4):575-591. doi:10.1007/s12369-014-0242-2

112. Pearce AJ, Adair B, Miller K, et al. Robotics to enable older adults to remain living at home. J Aging Res. 2012;2012:538169. doi:10.1155/2012/538169

113. Kachouie R, Sedighadeli S, Khosla R, Chu MT. Socially assistive robots in elderly care: a mixed-method systematic literature review. Int J Hum Comput Interact. 2014;30(5):369-393. doi:10.1080/10447318.2013.873278 
114. Gustafsson C, Svanberg C, Müllersdorf M. Using a robotic cat in dementia care. J Gerontol Nurs. 2015;41(10):46-56. doi:10.3928/ 00989134-20150806-44

115. Shukla J, Barreda-Ángeles M, Oliver J, Puig D Effectiveness of socially assistive robotics during cognitive stimulation interventions: impact on caregivers. Paper presented at: 2017 26th IEEE International Symposium on Robot and Human Interactive Communication (ROMAN); August 28, 2017-September 1, 2017; 2017.

116. Valenti SM, Aguera-Ortiz L, Olazaran RJ, et al. Social robots in advanced dementia. Front Aging Neurosci. 2015;7.

117. Baisch S, Kolling T, Rühl S, et al. Emotional robots in a nursing context: empirical analysis of the present use and the effects of Paro and Pleo. $Z$ Gerontol Geriatr. 2018;51(1):16-24. doi:10.1007/s00391-017-1346-8

118. Jøranson N, Pedersen I, Rokstad AMM, Ihlebæk C. Effects on symptoms of agitation and depression in persons with dementia participating in robot-assisted activity: a cluster-randomized controlled trial. J Am Med Dir Assoc. 2015;16(10):867-873. doi:10.1016/j.jamda.2015.05.002

119. Petersen S, Houston S, Qin H, Tague C, Studley J. The utilization of robotic pets in dementia care. J Alzheimer's Dis. 2016;55 (2):569-574. doi:10.3233/JAD-160703

120. Moyle W, Jones CJ, Murfield JE, et al. Use of a robotic seal as a therapeutic tool to improve dementia symptoms: a cluster-randomized controlled trial. $J$ Am Med Dir Assoc. 2017;18(9):766-773. doi:10.1016/j.jamda.2017.03.018

121. Broadbent E, Orejana JR, Ahn HS, Xie J, Rouse P, MacDonald BA The cost-effectiveness of a robot measuring vital signs in a rural medical practice. Paper presented at: 2015 24th IEEE International Symposium on Robot and Human Interactive Communication (RO-MAN); August 31, 2015September 4, 2015; 2015.

122. Bettinelli M, Lei Y, Beane M, Mackey C, Liesching T. Does robotic telerounding enhance nurse-physician collaboration satisfaction about care decisions? Telemed J e-Health. 2015;21 (8):637-643. doi:10.1089/tmj.2014.0162

123. Summerfield MR, Seagull FJ, Vaidya N, Xiao Y. Use of pharmacy delivery robots in intensive care units. Am J Health Syst Pharm. 2011;68(1):77-83. doi:10.2146/ajhp100012

124. Wang RH, Gorski SM, Holliday PJ, Fernie GR. Evaluation of a contact sensor skirt for an anti-collision power wheelchair for older adult nursing home residents with dementia: safety and mobility. Assist Technol. 2011;23(3):117-134. doi:10.1080/10400435.2010.541406

125. Pickham D, Berte N, Pihulic M, Valdez A, Mayer B, Desai M. Effect of a wearable patient sensor on care delivery for preventing pressure injuries in acutely ill adults: a pragmatic randomized clinical trial (LS-HAPI study). Int J Nurs Stud. 2018;80:12-19. doi:10.1016/j.ijnurstu.2017.12.012

126. Marra AR, Sampaio Camargo TZ, Magnus TP, et al. The use of real-time feedback via wireless technology to improve hand hygiene compliance. Am J Infect Control. 2014;42(6):608-611. doi:10.1016/j.ajic.2014.02.006

127. Sahota O, Drummond A, Kendrick D, et al. REFINE (REducing Falls in In-patieNt Elderly) using bed and bedside chair pressure sensors linked to radio-pagers in acute hospital care: a randomised controlled trial. Age Ageing. 2014;43(2):247-253. doi:10.1093/ageing/aft155

128. Shee AW, Phillips B, Hill K, Dodd K. Feasibility, acceptability, and effectiveness of an electronic sensor bed/chair alarm in reducing falls in patients with cognitive impairment in a subacute ward. $J$ Nurs Care Qual. 2014;29(3):253-262. doi:10.1097/NCQ.0000000000000054

129. Tchalla AE, Lachal F, Cardinaud N, Saulnier I, Rialle V, Preux P-M. Preventing and managing indoor falls with homebased technologies in mild and moderate Alzheimer's disease patients: pilot study in a community dwelling. Dement Geriatr Cogn Disord. 2013;36(3-4):251-261. doi:10.1159/000351863
130. Hardin SR, Dienemann J, Rudisill P, Mills K. Inpatient fall prevention: use of in-room Webcams. J Patient Saf. 2013;9 (1):29-35.

131. van der Lende M, Cox FME, Visser GH, Sander JW, Thijs RD. Value of video monitoring for nocturnal seizure detection in a residential setting. Epilepsia. 2016;57(11):1748-1753. doi:10.1111/epi.13558

132. Lexis M, Everink I, van der Heide L, Spreeuwenberg M, Willems C, de Witte L. Activity monitoring technology to support homecare delivery to frail and psychogeriatric elderly persons living at home alone. Technol Disabil. 2013;25(3):189-197. doi:10.3233/TAD-130377

133. Rantz M, Phillips LJ, Galambos C, et al. Randomized trial of intelligent sensor system for early illness alerts in senior housing. J Am Med Dir Assoc. 2017;18(10):860-870. doi:10.1016/j. jamda.2017.05.012

134. Lazarou I, Karakostas A, Stavropoulos TG, et al. A novel and intelligent home monitoring system for care support of elders with cognitive impairment. $J$ Alzheimers Dis. 2016;54 (4):1561-1591. doi:10.3233/JAD-160348

135. Brown H, Terrence J, Vasquez P, Bates DW, Zimlichman E. Continuous monitoring in an inpatient medical-surgical unit: a controlled clinical trial. Am J Med. 2014;127(3):226-232. doi:10.1016/j.amjmed.2013.12.004

136. Zhou J, Liu DB, Zhong JW, et al. Feasibility of a remote monitoring system for home-based non-invasive positive pressure ventilation of children and infants. Int $J$ Pediatr Otorhinolaryngol. 2012;76(12):1737-1740. doi:10.1016/j.ijporl.2012.08.012

137. Kuroda T, Noma H, Naito C, et al. Prototyping sensor network system for automatic vital signs collection: evaluation of a location based automated assignment of measured vital signs to patients. Methods Inf Med. 2013;52(3):239-249. doi:10.3414/ ME12-01-0096

138. Pigini L, Bovi G, Panzarino C, et al. Pilot test of a new personal health system integrating environmental and wearable sensors for telemonitoring and care of elderly people at home (SMARTA project). Gerontology. 2017;63(3):281-286. doi:10.1159/000455168

139. Jousselme C, Vialet R, Jouve E, Lagier P, Martin C, Michel F. Efficacy and mode of action of a noise-sensor light alarm to decrease noise in the pediatric intensive care unit: a prospective, randomized study. Pediatr Crit Care Med. 2011;12(2):e69-e72. doi:10.1097/PCC.0b013e3181e89d91

140. Pot AM, Willemse BM, Horjus S. A pilot study on the use of tracking technology: feasibility, acceptability, and benefits for people in early stages of dementia and their informal caregivers. Aging Ment Health. 2012;16(1):127-134. doi:10.1080/ 13607863.2011.596810

141. Osaimi AAA, Kadi KA, Saddik B Role of radio frequency identification in improving infant safety and the extent of nursing staff acceptance of RFID at King Abdulaziz medical city in Riyadh. Paper presented at: 2017 International Conference on Informatics, Health \& Technology (ICIHT); February 21-23, 2017; 2017.

142. Kosse NM, Brands K, Bauer JM, Hortobagyi T, Lamoth CJC. Sensor technologies aiming at fall prevention in institutionalized old adults: a synthesis of current knowledge. Int J Med Inform. 2013;82(9):743-752. doi:10.1016/j.ijmedinf.2013.06.001

143. Walia GS, Wong AL, Lo AY, et al. Efficacy of monitoring devices in support of prevention of pressure injuries: systematic review and meta-analysis. Adv Skin Wound Care. 2016;29(12):567-576. doi:10.1097/01.ASW.0000504579.83707.f6

144. Marek K, Stetzer F, Ryan P, et al. Nurse care coordination and technology effects on health status of frail older adults via enhanced self-management of medication: randomized clinical trial to test efficacy. Nurs Res. 2013;62(4):269-278. doi:10.1097/NNR.0b013e318298aa55 
145. Akiyama M, Sasaki Y Efficacy of the drug administration support system for improving drug compliance in home-care. Paper presented at: 2013 Proceedings of PICMET '13: Technology Management in the IT-Driven Services (PICMET); July 28, 2013-August 1, 2013; 2013.

146. Suzuki S, Yokoishi T, Hada H, Mitsugi J, Nakamura O, Murai J Bidirectional medication support system for medical staff and home care patients. Paper presented at: 2011 5th International Symposium on Medical Information and Communication Technology; March 27-30, 2011; 2011.

147. Vadiei N, Shuman C, Murthy M, Daley M. Optimization of intelligent infusion pump technology to minimize vasopressor pump programming errors. Expert Opin Drug Saf. 2017:1-5.

148. Orto V, Hendrix CC, Griffith B, Shaikewitz ST. Implementation of a smart pump champions program to decrease potential patient harm. J Nurs Care Qual. 2015;30(2):138-143. doi:10.1097/ NCQ.0000000000000090

149. Miller K, Rodger S, Kipping B, Kimble RM. A novel technology approach to pain management in children with burns: a prospective randomized controlled trial. Burns. 2011;37 (3):395-405. doi:10.1016/j.burns.2010.12.008

150. Zimmermann C, Zeilfelder J, Bloecher T, Diehl M, Essig S, Stork W Evaluation of a smart drink monitoring device. Paper presented at: 2017 IEEE Sensors Applications Symposium (SAS); March 13-15, 2017; 2017.

151. Van der Roest HG, Wenborn J, Pastink C, Droes RM, Orrell M. Assistive technology for memory support in dementia. Cochrane Database Syst Rev. 2017;6:Cd009627.

152. Kipping B, Rodger S, Miller K, Kimble RM. Virtual reality for acute pain reduction in adolescents undergoing burn wound care: a prospective randomized controlled trial. Burns. 2012;38 (5):650-657. doi:10.1016/j.burns.2011.11.010

153. Mazzacano SD, McSherry T, Atterbury M, Helmold E, Gartner S, Schulman C. Effect of virtual reality distraction therapy on pain and anxiety in adult patients undergoing complex dressing changes: a randomized controlled trial. J Burn Care Res. 2016;37:S157.

154. Patterson D, Soltani M, Teeley A, Morse D, Wiechman S, Gibran N. Hypnosis delivered through immersive virtual reality for wound care: a randomized, controlled study. J Burn Care Res. 2012;33(2 suppl. 1):S70.
155. Moyle W, Bramble M, Jones C, Murfield J. Care staff perceptions of a social robot called Paro and a look-alike Plush Toy: a descriptive qualitative approach. Aging Ment Health. 2016;1-6.

156. Lapierre N, Neubauer N, Miguel-Cruz A, Rios Rincon A, Liu L, Rousseau J. The state of knowledge on technologies and their use for fall detection: a scoping review. Int $J$ Med Inform. 2018;111:58-71. doi:10.1016/j.ijmedinf.2017.12.015

157. Anttila H, Samuelsson K, Salminen A-L, Brandt Å. Quality of evidence of assistive technology interventions for people with disability: an overview of systematic reviews. Technol Disabil. 2012;24(1):9-48. doi:10.3233/TAD-2012-0332

158. Schulz R, Wahl H-W, Matthews JT. Advancing the aging and technology agenda in gerontology. Gerontologist. 2015;55 (5):724-734. doi:10.1093/geront/gnu071

159. Lehnert T, Heuchert M, Hussain K, Koenig -H-H. Stated preferences for long-term care: a literature review. Ageing Soc. 2019;39 (9):1873-1913. doi:10.1017/S0144686X18000314

160. Vawdrey DK, Hripcsak G. Publication bias in clinical trials of electronic health records. J Biomed Inform. 2013;46(1):139-141. doi:10.1016/j.jbi.2012.08.007

161. McNamee P, Murray E, Kelly MP, et al. Designing and undertaking a health economics study of digital health interventions. Am J Prev Med. 2016;51(5):852-860. doi:10.1016/j. amepre.2016.05.007

162. Frieden TR, Drazen JM, Harrington DP, McMurray JJV, Ware JH, Woodcock J. Evidence for health decision making-beyond randomized, controlled trials. $N$ Engl J Med. 2017;377(5):465-475. doi:10.1056/NEJMra1614394

163. Riley WT, Glasgow RE, Etheredge L, Abernethy AP. Rapid, responsive, relevant (R3) research: a call for a rapid learning health research enterprise. Clin Transl Med. 2013;2(1):10. doi:10.1186/2001-1326-2-10

164. Greenhalgh T, Wherton J, Papoutsi C, et al. Analysing the role of complexity in explaining the fortunes of technology programmes: empirical application of the NASSS framework. BMC Med. 2018;16(1):66. doi:10.1186/s12916018-1050-6

\section{Publish your work in this journal}

The Journal of Multidisciplinary Healthcare is an international, peerreviewed open-access journal that aims to represent and publish research in healthcare areas delivered by practitioners of different disciplines. This includes studies and reviews conducted by multidisciplinary teams as well as research which evaluates the results or conduct of such teams or healthcare processes in general. The journal covers a very wide range of areas and welcomes submissions from practitioners at all levels, from all over the world. The manuscript management system is completely online and includes a very quick and fair peer-review system. Visit http://www.dovepress.com/testimonials. php to read real quotes from published authors. 